\section{A DUPLA CARREIRA ACADÊMICO-ESPORTIVA NA AMÉRICA LATINA ENTRE OS ANOS 2000 E 2020: ANÁLISE SOBRE A PRODUÇÃO CIENTÍFICA PUBLICADA EM ARTIGOS}

\author{
ACADEMIC-SPORTS DUAL CAREER IN LATIN AMERICA BETWEEN \\ 2000 AND 2020: ANALYSIS ON THE SCIENTIFIC PRODUCTION \\ PUBLISHED IN ARTICLES C? \\ LA CARRERA DUAL ACADÉMICO-DEPORTIVA EN AMÉRICA LATINA \\ ENTRE LOS AÑOS 2000 Y 2020: ANÁLISIS DE LA PRODUCCIÓN \\ CIENTÍFICA PUBLICADA EN ARTÍCULOS C? \\ doi) https://doi.org/10.22456/1982-8918.117028
}

(iD) Christiano Streb Ricci* <csricci@hotmail.com>

Rodrigo Aquino** <aquino.rlq@gmail.com>

(D) Renato Francisco Rodrigues Marques*** <renatomarques@usp.br>

\footnotetext{
*Universidade Estadual de Campinas (Unicamp). Campinas, SP, Brasil.

**Universidade Federal do Espírito Santo (UFES). Vitória, ES, Brasil..

***Universidade de São Paulo. Ribeirão Preto, SP, Brasil.
}

\begin{abstract}
Resumo: O presente estudo analisou a produção científica sobre dupla carreira acadêmico-esportiva em artigos oriundos da América Latina publicados em periódicos acadêmicos entre os anos 2000 e 2020. A seleção e análise dos artigos seguiram os métodos/protocolo ENTREQ, Análise Temática Reflexiva e Análise de Redes Sociais. Oito bases de dados foram pesquisadas e 39 artigos selecionados. Os resultados indicam: a) os primeiros trabalhos encontrados datam de 2011 ; b) os estudos se concentram principalmente no Brasil; c) a interação entre pesquisadores latino-americanos é pequena; d) predominam as abordagens qualitativas; e) as categorias de base e a Educação Básica são os contextos mais investigados; f) predominam estudos com modalidades esportivas praticadas por homens, especialmente o futebol. Conclui-se que os tópicos analisados neste trabalho apresentam um panorama sobre a produção acadêmica em artigos sobre dupla carreira acadêmico-esportiva na América Latina, ao mesmo tempo em que destaca lacunas importantes a serem preenchidas por futuros estudos.
\end{abstract}

Palavras chave: Indicadores de Produção científica. Atletas. Esportes. Pesquisadores.
Recebido em: 22 jul. 2021 Aprovado em: 10 jan. 2022 Publicado em: 09 fev. 2022

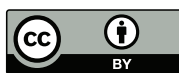

Este é um artigo publicado sob a licença Creative Commons Atribuição 4.0 Internacional (CC BY 4.0). 


\section{INTRODUÇÃO}

A dupla carreira consiste no investimento de indivíduos em duas carreiras simultâneas em distintas áreas de atuação, por exemplo, a acadêmica e a esportiva (STAMBULOVA; WYLLEMAN, 2015), resultando em tensões e desafios (COELHO et al., 2021; MATEU et al., 2020).

Em sentido ampliado, carreiras são padrões irregulares de experiências rotineiras, intercaladas com pontos de inflexão (HODKINSON; SPARKES, 1997). A carreira acadêmica, nesta perspectiva, diz respeito aos processos formais de aprendizagem e incorporação cultural, comprovados por níveis de certificação (HODKINSON; BIESTA; JAMES, 2007). A carreira esportiva, por sua vez, considera o investimento na melhoria do desempenho atlético e constante participação em competições (ALFERMANN; STAMBULOVA, 2007). Para alcançar o nível de desempenho de elite esportivo, exige-se muito esforço e investimento de tempo, o que dificulta a participação em outras atividades (ANDERSSON; BARKER-RUCHTI, 2018). Combinar as carreiras esportiva e acadêmica é um dos principais desafios que aspirantes a atletas de elite enfrentam entre os 12 e 25 anos de idade (RYBA et al., 2017). Diversas situações provocadas por essa dedicação precisam ser organizadas pelos atletas e agentes sociais à sua volta (GUIDOTTI; CORTIS; CAPRANICA, 2015), de forma a não prejudicar o envolvimento em nenhuma delas (MATEU; VILANOVA; INGLÊS, 2018).

Os estudos sobre as tensões próprias da dupla carreira acadêmico-esportiva surgiram na década de 1970, na Europa e nos Estados Unidos (GUIDOTTI; CORTIS; CAPRANICA, 2015; STAMBULOVA; WILLEMANN, 2019). A preocupação com essa temática vem ganhando espaço (MORRIS, et al., 2020). Em alguns países europeus é possível observar políticas públicas e projetos destinados a estudantes-atletas, como programas de bolsas de estudo, aulas especiais, educação à distância, formas alternativas de avaliação, tutorias e parcerias de instituições esportivas com escolas, universidades e instituições acadêmicas (CAPUT-JOGUNICA; ĆURKOVIĆ; BJELIĆ, 2012; LINNÉR et al., 2019; MATEU et al., 2020; MIRÓ MOYÁ et al., 2018; SÁNCHEZ PATO et al., 2018).

Parte de outro contexto social, a América Latina se coloca em uma posição diferente em relação à Europa e aos Estados Unidos no que se refere às desigualdades sociais e de concentração de riquezas, apresentando a distribuição de renda mais desigual entre as regiões avaliadas pelo índice de Gini' (CEPAL, 2018; MATTEI, 2017). Apesar do crescimento médio demonstrado no Índice de Desenvolvimento Humano $(\text { IDH })^{2}$ entre os anos de 2010 e 2014 (SANTOS et al., 2018), muitos dos países latinoamericanos ainda se encontram nas piores posições do globo. Em relação à Europa, por exemplo, enquanto oito em cada dez países europeus estão classificados com

10 Índice de Gini, criado pelo matemático italiano Conrado Gini, é um instrumento para medir o grau de concentração de renda em determinado grupo. Indica a diferença entre os rendimentos dos mais pobres e dos mais ricos. Varia de zero a um (alguns apresentam de zero a cem). O valor zero representa a situação de igualdade, ou seja, todos têm a mesma renda (IPEA, 2004).

2 O IDH é uma medida comparativa usada para classificar os países pelo seu grau de desenvolvimento, são quatro classificações: "muito alto"; "alto"; "médio"; e "baixo". Para o cálculo do índice são abordadas três dimensões: saúde; educação; e economia (PNUD, 2014). 
o IDH muito alto, somente um em cada dez países latino-americanos estão nesta mesma classificação (PNUD, 2014). Portanto, análises sobre processos de dupla carreira acadêmico-esportiva na América Latina devem considerar tais indicadores socioeconômicos, problemas de acesso à educação formal de boa qualidade por boa parte da população (MARTÍNEZ; TRUCCO; PALMA, 2014; ROSSETTI, 2014) e a carência de políticas públicas de oferecimento do esporte em diferentes níveis de prática (ROCHA, et al, 2020).

No contexto latino-americano existem estudos dedicados à dupla carreira acadêmico-esportiva (AGUILAR; FLÁNDEZ, 2020; CADAVID; COSTA; CARNEIRO, 2021; CANTOR, 2016; COELHO et al., 2021; CORREIA; SOARES, 2020; COSTA; ROCHA; CADAVID, 2018; CORTES DÍAZ; GALAK, 2021; HAAS; CARVALHO, 2018; LAGOS CÓRTES, 2014; LAÍÑO et al., 2019; MAQUIAVELI et al., 2021; MARQUES et al., 2021; MARTINS et al., 2021; MELO; ROCHA; ROMÃO, 2020; MIRANDA; SANTOS; COSTA, 2020; MURZI; HERBELLA; SUSTAS, 2020; RASTELLI; BANDEIRA, 2019; ROCHA; MIRANDA; COSTA E SILVA, 2020; SOARES, et al., 2011, 2013), no entanto, um aprofundamento do que significa essa produção pode favorecer o entendimento de como se encontra esse objeto de estudo em tal região.

Desta forma, um mapeamento sobre os modos de investigação e dos objetos estudados pode sustentar uma melhor compreensão sobre os desafios, barreiras e tensões enfrentadas por estudantes-atletas latino-americanos e colaborar com o desenvolvimento de planos e intervenções que os auxiliem a superar tais dificuldades (GUIDOTTI; COSTIS; CAPRANICA, 2015; STAMBULOVA; WILLEMAN, 2019). Deste modo, a questão norteadora deste estudo é: Como se caracteriza a produção acadêmico-científica sobre dupla carreira acadêmico-esportiva na América Latina?

O objetivo geral deste estudo foi analisar a produção científica sobre dupla carreira acadêmico-esportiva na América Latina publicada em formato de artigos por periódicos acadêmicos entre os anos 2000 e 2020. Os objetivos específicos são: a) identificar a distribuição cronológica e os países de origem das publicações; b) mapear a distribuição geográfica dos pesquisadores e possíveis interações entre eles; c) identificar as abordagens de pesquisa utilizadas; d) identificar os ambientes e contextos de prática esportiva e grau acadêmico; e) caracterizar as temáticas e tópicos tratados nos estudos.

\section{MÉTODO}

A presente revisão sistemática foi pautada no protocolo Enhancing Transparency in Reporting the Synthesis of Qualitative Research (ENTREQ) (TONG, et al., 2012) e na Análise Temática Reflexiva (BRAUN; CLARKE, 2006; 2012; 2019). Foram analisados artigos sobre dupla carreira acadêmico-esportiva relacionados ao contexto latino-americano e publicados em periódicos acadêmicos entre os anos 2000 e 2020, caracterizando um recorte temporal que sinalize conhecimento atualizado sobre a temática.

A revisão sistemática organizou-se em duas etapas principais. Primeiro selecionaram-se e caracterizaram-se os estudos com base no ENTREQ, ferramenta 
metodológica que consiste em 21 itens (Apêndice 1) agrupados em cinco domínios principais: Domínios 1 e 2 (introdução, métodos e metodologia); Domínio 3 (pesquisa e seleção de literatura); Domínio 4 (avaliação); e Domínio 5 (síntese dos achados). O protocolo permite que a metodologia e as abordagens para a análise dos estudos selecionados se relacionem com a questão de pesquisa, com os tipos de dados disponíveis, com a posição filosófica do pesquisador, com o contexto e com o públicoalvo do estudo (TONG, et al., 2012).

A abordagem de busca utilizada através do ENTREQ foi a pré-planejada, de estratégia abrangente. Os critérios de inclusão dos artigos foram: i) artigos publicados em periódicos acadêmicos que tratassem da conciliação dos compromissos esportivos e acadêmicos em diferentes contextos de estudantes-atletas na América Latina; ii) artigos publicados entre os anos 2000 e 2020; iii) artigos publicados em português e/ou inglês e/ou espanhol. As bases de dados utilizadas foram: Lilacs; Portal de Periódicos da Capes; Psicoynfo; PubMED; Redalyc; Redib; SciELO; e Scopus. Os descritores utilizados se encontram no Quadro 1.

Quadro 1 - Descritores utilizados nos três idiomas para as buscas nas bases de dados.

\begin{tabular}{|c|c|c|}
\hline Termos em espanhol & Termos em inglês & Termos em português \\
\hline Estudiante atleta & Student athlete & Atleta-estudante \\
Estudiante atleta & Athlete student & Estudante-atleta \\
Deportista universitario & University athlete & Atleta universitário \\
Carrera académica & Academic career & Carreira acadêmica \\
Carrera académica de los & Academic career of & Carreira acadêmica de \\
deportistas & athletes & atletas \\
Carrera escolar & School career & Carreira escolar \\
Carrera deportiva & Sports career & Carreira esportiva \\
Carrera dual & Dual career & Dupla carreira \\
Carrera deportiva dual & Dual sports career & Dupla carreira esportiva \\
Escolaridad de deportistas & Athletes' schooling & Escolaridade de atletas \\
Escolarización de deportistas & Schooling of athletes & Escolarização de atletas \\
Trayectoria deportiva y & Sporting trajectory and & Trajetória esportiva e \\
escolaridad & schooling & escolaridade \\
Trayectoria deportiva y & Sporting trajectory and & Trajetória esportiva e \\
universitaria & university & universidade \\
\hline
\end{tabular}

Fonte: Dados da pesquisa.

O processo de triagem para a localização dos estudos foi realizado por três pesquisadores. Dois envolvidos nas buscas e análises (primeiro e segundo autores do estudo) e um pesquisador sênior (terceiro autor) que solucionou os impasses e ratificou as escolhas realizadas. Os pesquisadores utilizaram os mesmos termos de buscas nas mesmas bases de dados, e conferiram os títulos e resumos dos estudos para a primeira seleção de trabalhos. Utilizou-se o coeficiente de kappa ${ }^{3}$, que atingiu o valor 1,0 de concordância para a consolidação dos achados entre os pesquisadores.

3 Foi utilizado o software IBM SPSS Statistics (versão 22.0 - IBM Corporation®) para análise da concordância entre os pesquisadores, por meio do coeficiente de kappa de Cohen (k). 
Inicialmente foram encontrados 3.779 artigos nos três idiomas. Após leitura dos títulos e resumos de todos os artigos, foram excluídos da análise por incompatibilidade ao tema ou duplicação 3.733 artigos, e 46 foram selecionados para leitura na íntegra. Na última etapa de seleção de trabalhos, foram excluídos sete estudos por incompatibilidade, restando 39 artigos como corpo de dados final para análise (Figura 1).

Figura 1 - Fluxograma com os resultados do processo de seleção dos estudos.

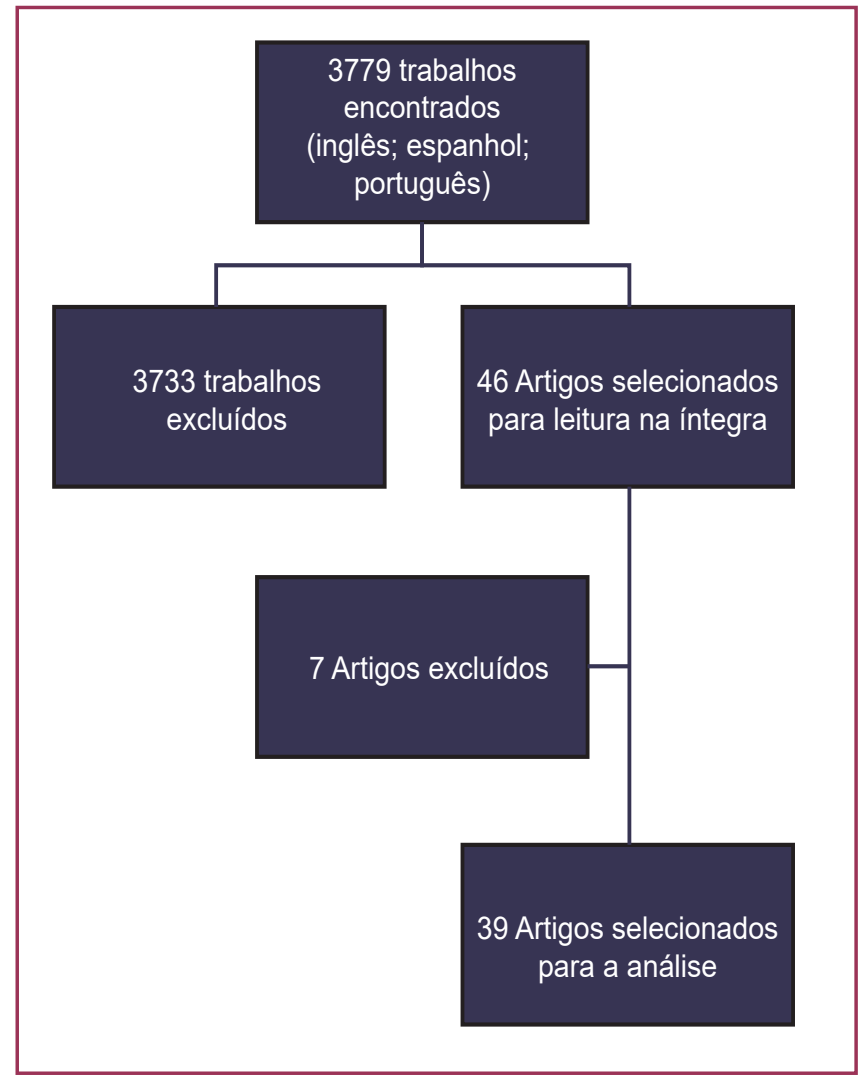

Fonte: Dados da pesquisa

Na segunda etapa, utilizou-se a Análise Temática Reflexiva para os itens do protocolo ENTREQ que envolvem codificação, derivação de temas, citações/menções e produção de síntese. Essa análise também foi utilizada para identificar, analisar e relatar padrões dentro do corpo de dados, de acordo com os objetivos do estudo (BRAUN; CLARK, 2006; 2019). Além disso, foi empregada a análise de redes sociais para verificar as relações entre os(as) pesquisadores(as) sobre esse tema. Uma rede de colaboração científica é uma rede em que os "nós" são os(as) autores(as) e os "links" são as coautorias. Esta é uma das formas mais bem documentadas de colaboração científica (GLÄNZEL; SCHUBERT, 2005). Para tal procedimento foi utilizado o software Gephi (versão 0.9.2).

\section{RESULTADOS E DISCUSSÃO}

Os resultados se apresentam em dois temas. O primeiro, "Especificações dos artigos encontrados", sintetiza os achados e é composto por quatro 
subtemas: "Cronologia e origem das publicações"; "Autores(as) e suas conexões"; "Caracterização das abordagens metodológicas"; "Ambientes e contextos de prática esportiva e grau acadêmico dos(as) estudantes-atletas". O segundo tema apresenta os conteúdos e objetos de estudos dos artigos e se intitula "Barreiras e facilitadores da dupla carreira acadêmico-esportiva na América Latina".

\subsection{TEMA 1: ESPECIFICAÇÕES DOS ARTIGOS ENCONTRADOS}

Esta seção caracteriza os artigos encontrados. No Apêndice 2 encontra-se o quadro completo com as especificações detalhadas dos trabalhos.

\subsubsection{Cronologia e origem das publicações}

A Figura 2 agrupa e quantifica as publicações por período (2000-2010; 2011$2015 ; 2016-2020)$.

Figura 2 - Ordem cronológica e quantitativa das publicações.

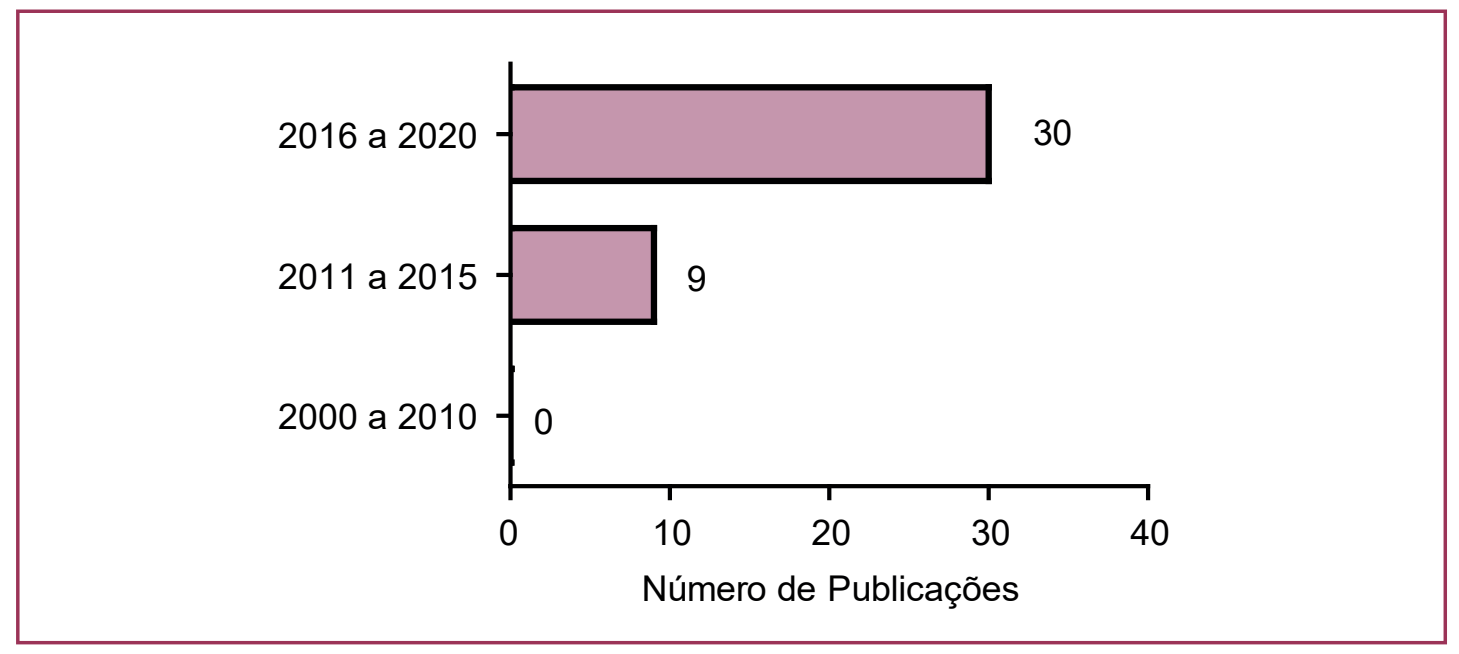

Fonte: Dados da pesquisa

Os primeiros trabalhos encontrados datam de 2011 (ROCHA; BARTHOLO; MELO, 2011; SOARES et al., 2011), na Europa e nos Estados Unidos tem-se artigos dessa temática desde a década de 1970 (AZEVEDO et al., 2017). Observa-se na América Latina uma tendência de aumento no número de publicações, especialmente nos últimos cinco anos.

O Quadro 2 apresenta as nacionalidades: dos países onde foram realizados os estudos; das revistas nas quais os artigos foram publicados; dos(as) autores(as); e o idioma de divulgação. 
Quadro 2 - Origem das publicações: artigos, periódicos, autores(as) e idiomas de divulgação

\begin{tabular}{|c|c|c|c|c|}
\hline & $\begin{array}{c}\text { Nacionalidade do } \\
\text { estudo }\end{array}$ & $\begin{array}{c}\text { Nacionalidade dos } \\
\text { Periódicos }\end{array}$ & $\begin{array}{c}\text { Nacionalidade } \\
\text { dos/as autores/as }\end{array}$ & $\begin{array}{c}\text { Idioma de } \\
\text { divulgação }\end{array}$ \\
\hline Países e & Brasil: 32 & Brasil: 19 & Brasil: 66 & Português: 30 \\
& Colômbia: 3 & Colômbia: 2 & Argentina: 7 & Espanhol: 8 \\
& Argentina: 2 & México: 2 & Colômbia: 4 & Inglês: 1 \\
& Chile: 1 & Argentina: 1 & Chile: 2 & \\
& Cuba: 1 & Chile: 1 & Cuba: 2 & \\
& & Cuba: 1 & Peru: 1 & \\
\hline Total & $\mathbf{3 9}$ artigos & 27 Periódicos & $\mathbf{8 2}$ autores/as & $\mathbf{3 9}$ artigos \\
\hline
\end{tabular}

Fonte: Dados da pesquisa.

Há uma notável concentração de produções oriundas e publicadas no Brasil, que é o local de origem de $80,5 \%$ dos(as) autores(as) e local de realização de $82 \%$ dos estudos. Além disso, $70 \%$ dos periódicos em que os artigos foram publicados são brasileiros, de modo que o idioma predominante na divulgação dos artigos é o português.

Um ranking que avaliou 177 universidades latino-americanas, nos âmbitos do ensino, da pesquisa, da transferência de conhecimento e da perspectiva internacional, indica que o Brasil tem 29 instituições entre as 50 mais bem avaliadas (LATIN AMERICA UNIVERSITY RANKINGS, 2021), o que proporciona um maior fluxo de produção de artigos no país, fato que pode repercutir sobre os resultados encontrados. Além disso, o movimento causado pelos megaeventos organizados no Brasil ${ }^{4}$ estimulou a produção acadêmica brasileira em diversos temas relacionados ao esporte (AZEVEDO et al., 2017; MIRANDA; SANTOS; COSTA, 2020).

Apesar do crescente interesse, os estudos sobre dupla carreira ainda são recentes na América Latina em comparação à Europa, que atualmente já apresenta ações continentais integradas. Essas colaborações se fortaleceram principalmente após o ano de 2007, com a produção e divulgação de um documento sobre o papel do esporte na Comunidade Europeia (COMMISION OF THE EUROPEAN COMMUNITIES, 2007). Cinco anos depois, um guia de recomendações para a dupla carreira na Europa foi produzido (EUROPEAN COMISSION, 2012).

\subsubsection{Autores(as) e suas conexões}

A Figura 3 demonstra a rede de colaborações entre os(as) autores(as) das publicações analisadas.

4 Jogos Pan-americanos (2007); Jogos Mundiais Militares (2011); Copa das Confederações de Futebol masculino (2013); Copa do Mundo de Futebol masculino (2014); Jogos Olímpicos de Verão (2016); Jogos Paralímpicos de Verão (2016). 
Figura 3 - Rede de colaboração dos(as) 82 autores(as) sobre a dupla carreira acadêmico-esportiva na América Latina.

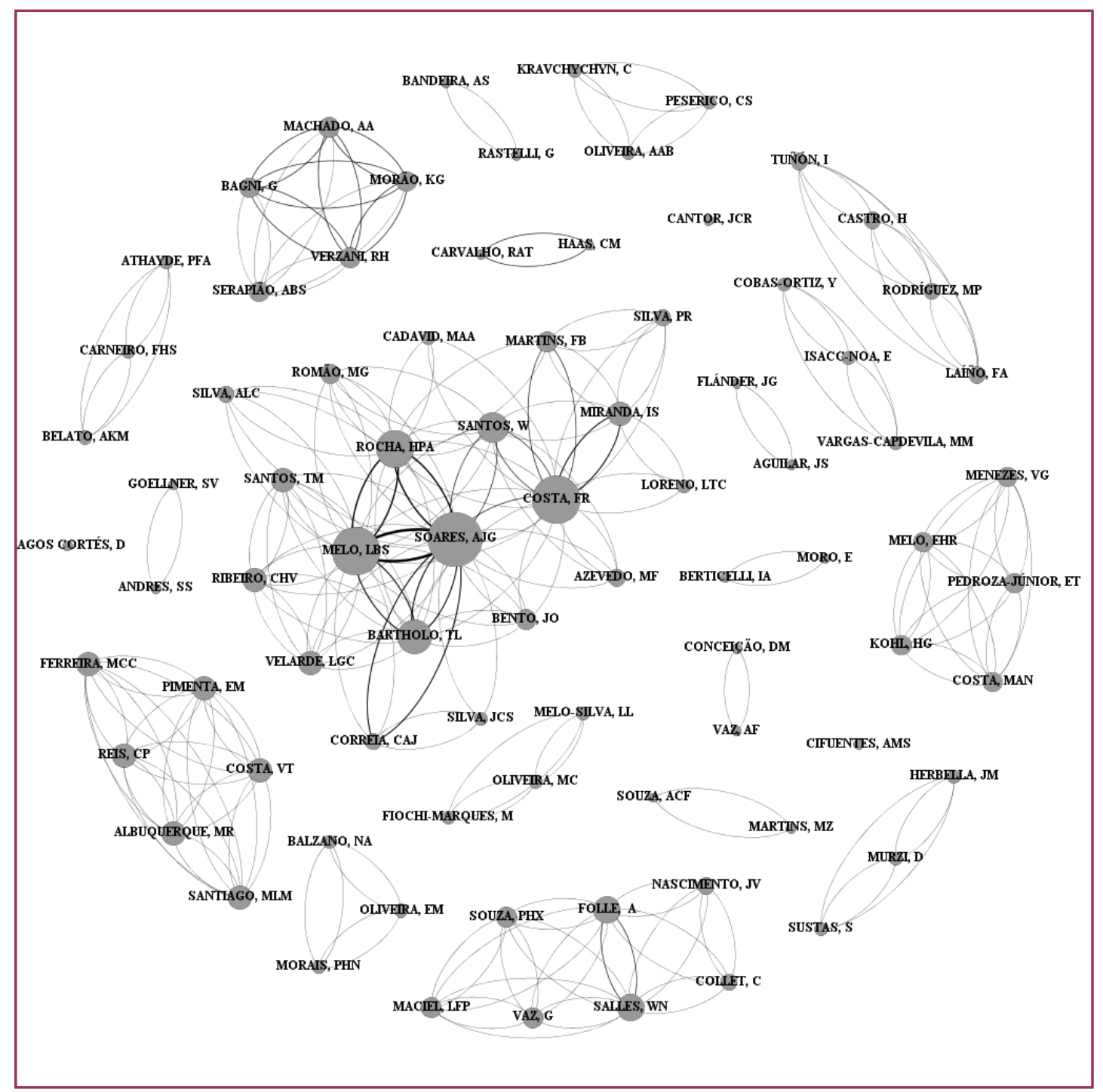

Fonte: Dados da pesquisa.

As interações entre os(as) autores(as) ocorreram principalmente dentro de seus próprios países, exceção feita a dois trabalhos, um entre Brasil e Colômbia (MIRANDA et al., 2018) e outro entre Brasil e Peru (SOARES et al., 2013), porém com as duas publicações tratando do contexto brasileiro.

A proporção entre homens e mulheres é desigual. Dos(as) 82 autores(as), 59 (72\%) são homens e 23 (28\%) mulheres. Percebe-se o campo acadêmico como um espaço de reserva masculina, e essa situação começa a ser questionada a partir do final do século XX e início do XXI (CHASSOT, 2004; SILVA, 2012). Essa desproporção se assemelha ao cenário latino-americano de publicações, em que cerca de $20 \%$ são de autoria de mulheres e 80\% de homens (ESTÉBANEZ, 2003).

Destacam-se no cenário de produções sobre a dupla carreira o Laboratório de Pesquisa em Educação do Corpo da Universidade Federal do Rio de Janeiro/ Brasil (LABEC) e o Grupo de Pesquisa sobre Dupla Carreira da Universidade Federal de Brasília/Brasil (DuCa). Esses dois grupos são responsáveis por quinze artigos 
(AZEVEDO et al., 2017; CORREIA; SILVA; SOARES, 2017; CORREIA; MELO; SOARES 2020; CORREIA; SOARES, 2020; COSTA et al., 2018; MARTINS; ROCHA; COSTA, 2020; MELO; SOARES; ROCHA, 2014; MELO; ROCHA; SILVA, 2016; MELO; ROCHA; ROMÃO, 2020; MIRANDA et al., 2018; MIRANDA; LORENO; COSTA, 2020; MIRANDA; SANTOS; COSTA, 2020; ROCHA; BARTHOLO; MELO, 2011; SOARES et al., 2011; 2013) e por conexões entre vinte autores(as) da rede. Ressalta-se também a Universidad Santo Tomás de Bogotá, na Colômbia, responsável pelos três artigos de seu país (CANTOR, 2016; CIFUENTES, 2014; LAGOS CÓRTEZ, 2014).

Os autores mais recorrentes são os pesquisadores Antônio Jorge Gonçalves Soares, Felipe Rodrigues da Costa, Leonardo Bernardes Silva de Melo e Hugo Paula de Almeida Rocha.

\subsubsection{Abordagens metodológicas}

As abordagens metodológicas utilizadas nos trabalhos selecionados se encontram descritas no Quadro 3. Verificou-se maior incidência de trabalhos de abordagem qualitativa ou em combinação quantitativa-qualitativa.

Quadro 3- Abordagens metodológicas utilizadas nos artigos

\begin{tabular}{|c|c|c|}
\hline Método & $\begin{array}{c}\mathbf{N}^{\circ} \text { de } \\
\text { artigos }\end{array}$ & Autores(as) \\
\hline Qualitativo & 14 & $\begin{array}{l}\text { ANDRES; GOELLNER, 2018; CANTOR, 2016; CARVALHO; } \\
\text { HAAS, 2015; CIFUENTES, 2014; CORREIA; SILVA; SOARES, } \\
\text { 2017; CORREIA; MELO; SOARES, 2020; CORREIA; SOARES, } \\
\text { 2020; FIOCHI-MARQUES; OLIVEIRA; MELO-SILVA, 2018; } \\
\text { FOLLE et al., 2016; HAAS; CARVALHO, 2018; MIRANDA; } \\
\text { LORENO; COSTA, 2020; REIS et al., 2018; PEDROZA JÚNIOR } \\
\text { et al., 2020; ROCHA; BARTHOLO; MELO, } 2011 .\end{array}$ \\
\hline $\begin{array}{c}\text { Quantitativo- } \\
\text { Qualitativo }\end{array}$ & 11 & $\begin{array}{l}\text { BAGNI et al., 2020; BELATO; CARNEIRO; ATHAYDE, 2019; } \\
\text { CONCEIÇÃO; VAZ, 2020; LAGOS CÓRTEZ, 2014; COBAS- } \\
\text { ORTIZ; ISACC-NOA; VARGAS-CAPDEVILA, 2015; LAÍÑO et al., } \\
\text { 2019; MELO; SOARES; ROCHA, 2014; MELO; ROCHA; SILVA, } \\
\text { 2016; AGUILAR; FLÁNDEZ, 2020; PESERICO, KRAVCHYCHYN; } \\
\text { OLIVEIRA, 2015; SOARES et al., } 2013 .\end{array}$ \\
\hline Quantitativo & 7 & $\begin{array}{l}\text { MACIEL et al., 2017; MIRANDA; MARTINS; SILVA, 2018; } \\
\text { OLIVEIRA; BALZANO; MORAIS, 2018; SOUZA; MARTINS, 2018; } \\
\text { MELO; ROCHA; ROMÃO, 2020; MURZI; HERBELLA; SUSTAS, } \\
\text { 2020; VERZANI et al., } 2018 .\end{array}$ \\
\hline $\begin{array}{l}\text { Revisões } \\
\text { sistemáticas não } \\
\text { sistemáticas e } \\
\text { narrativas }\end{array}$ & 5 & $\begin{array}{c}\text { AZEVEDO et al., 2017; MARTINS; ROCHA; COSTA, 2020; } \\
\text { MIRANDA; SANTOS; COSTA, 2020; RASTELLI; BANDEIRA, } \\
\text { 2019; SOARES et al., } 2011 .\end{array}$ \\
\hline Editorial & 1 & COSTA; ROCHA; CADAVID, 2018 \\
\hline $\begin{array}{c}\text { Estudo } \\
\text { Cartográfico }\end{array}$ & 1 & MORO; BERTICELLI, 2019 \\
\hline
\end{tabular}

Fonte: Dados da pesquisa.

Identificaram-se também 14 artigos empíricos (ANDRES; GOELLNER, 2018; CANTOR, 2016; CARVALHO; HAAS, 2015; CIFUENTES, 2014; CORREIA; SILVA; SOARES, 2017; CORREIA; MELO; SOARES, 2020; CORREIA; SOARES, 
2020; FIOCHI-MARQUES; OLIVEIRA; MELO-SILVA, 2018; FOLLE et al., 2016; HAAS; CARVALHO, 2018; MIRANDA; LORENO; COSTA, 2020; REIS et al., 2018; PEDROZA JÚNIOR et al., 2020; ROCHA; BARTHOLO; MELO, 2011) e 11 teóricos (BAGNI et al., 2020; BELATO; CARNEIRO; ATHAYDE, 2019; CONCEIÇÃO; VAZ, 2020; LAGOS CÓRTEZ, 2014; COBAS-ORTIZ; ISACC-NOA; VARGAS-CAPDEVILA, 2015; LAIIÑO et al., 2019; MELO; SOARES; ROCHA, 2014; MELO; ROCHA; SILVA, 2016; AGUILAR; FLÁNDEZ, 2020; PESERICO, KRAVCHYCHYN; OLIVEIRA, 2015; SOARES et al., 2013).

3.1.4 Ambientes e contextos de prática esportiva e grau acadêmico dos(as) estudantes-atletas

Os artigos sobre os ambientes de prática esportiva se encontram no Quadro 5 e os de contexto acadêmico no Quadro 6.

Quadro 5 - Artigos e os ambientes de prática investigados

\begin{tabular}{|c|c|c|}
\hline $\begin{array}{c}\text { Ambientes de } \\
\text { prática }\end{array}$ & $\begin{array}{c}\mathbf{N}^{\circ} \text { de } \\
\text { artigos }\end{array}$ & Autores(as) \\
\hline Categorias de Base & 11 & $\begin{array}{r}\text { CORREIA; SILVA; SOARES, 2017; CORREIA; SOARES; } \\
\text { 2020; FOLLE et al., 2016; LAINO et al., 2019; MACIEL et } \\
\text { al., 2017; MELO; SOARES; ROCHA, 2014; MELO; ROCHA; } \\
\text { SILVA, 2016; ROCHA; BARTHOLO; MELO, 2011; SOARES et } \\
\text { al., 2011; 2013; VERZANI et al., 2018 }\end{array}$ \\
\hline $\begin{array}{c}\text { Categoria adulta: } \\
\text { Esporte de Elite }\end{array}$ & 6 & $\begin{array}{r}\text { ANDRES; GOELLNER, 2018; MARTINS; ROCHA; COSTA, } \\
\text { 2020; AGUILAR; FLÁNDEZ, 2020; PEDROZA JÚNIOR et al., } \\
\text { 2020; REIS et al., 2018; SOUZA; MARTINS, 2018 }\end{array}$ \\
\hline $\begin{array}{c}\text { Categorias de Base e } \\
\text { Categoria adulta }\end{array}$ & 5 & $\begin{array}{r}\text { CONCEIÇÃO; VAZ, 2020; MELO; ROCHA; ROMÃO, 2020; } \\
\text { MORO; BERTICELLI, 2019; MURZI; HERBELLA; SUSTAS, } \\
\text { 2020; OLIVEIRA; BALZANO; MORAIS, 2017 }\end{array}$ \\
\hline $\begin{array}{c}\text { Categoria adulta: } \\
\text { Esporte Universitário } \\
\text { e Esporte de Elite }\end{array}$ & 4 & $\begin{array}{r}\text { BELATO; CARNEIRO; ATHAYDE, 2019; COSTA; ROCHA; } \\
\text { CADAVID, 2018; HAAS; CARVALHO, 2018; MIRANDA; } \\
\text { MARTINS; SILVA, 2018 }\end{array}$ \\
\hline $\begin{array}{c}\text { Categoria adulta: } \\
\text { Esporte Universitário }\end{array}$ & 3 & $\begin{array}{r}\text { BAGNI et al., 2020; FIOCHI-MARQUES; OLIVEIRA; MELO- } \\
\text { SILVA, 2018; MIRANDA; LORENO; COSTA, 2020 }\end{array}$ \\
\hline $\begin{array}{c}\text { Esporte Escolar } \\
\text { Extracurricular }\end{array}$ & 1 & $\begin{array}{r}\text { PESERICO, KRAVCHYCHYN; OLIVEIRA, 2015 } \\
\hline\end{array}$ \\
\hline
\end{tabular}

Fonte: Dados da pesquisa

As Categorias de Base $^{5}$ marcam um momento importante nas definições e possibilidades do estudante-atleta em permanecer na carreira esportiva. Momento similar ao enfrentado na Educação Básica, principalmente nas transições e definições sobre a continuidade nos estudos (ALFERMANN; STAMBULOVA, 2007; FOLLE et al., 2016).

Nas categorias adultas, essa relação é mais diversificada, especialmente ao nível de exigência imposto ao(à) estudante-atleta que varia na frequência semanal e 
carga horária de treinos e competições (MIRANDA et al., 2018). Programas de apoio à dupla carreira identificam o(a) atleta de elite como aquele(a) que está inscrito(a) em alguma liga ou federação, ou participa de competições nacionais e internacionais, ou recebe apoios econômicos (CIFUENTES, 2014). No entanto, é importante considerar o sentido atribuído pelo(a) estudante-atleta aos seus compromissos esportivos (ANDRES; GOELLNER, 2018), pois, a depender do envolvimento, tensões na conciliação podem ocorrer mesmo com cargas horárias de treinos semanais menores (MATEU et al., 2020).

Quadro 6 - Artigos e os contextos acadêmicos

\begin{tabular}{|c|c|c|}
\hline $\begin{array}{c}\text { Contexto } \\
\text { educacional }\end{array}$ & $\begin{array}{c}\mathrm{N}^{\circ} \text { de } \\
\text { artigos }\end{array}$ & Autores(as) \\
\hline $\begin{array}{c}\text { Educação } \\
\text { Básica e Ensino } \\
\text { Superior }\end{array}$ & 13 & $\begin{array}{l}\text { ANDRES; GOELLNER, 2018; AZEVEDO et al., 2017; CARVALHO; } \\
\text { HAAS, 2015; FOLLE et al., 2016; MELO; ROCHA; SILVA, 2016; } \\
\text { MELO; ROCHA; ROMÃO, 2020; MORO; BERTICELLI, 2019; MURZI; } \\
\text { HERBELLA; SUSTAS, 2020; OLIVEIRA; BALZANO; MORAIS, 2017; } \\
\text { PEDROZA JÚNIOR et al., 2020; SOARES et al., 2011; 2013; SOUZA; } \\
\text { MARTINS, } 2018\end{array}$ \\
\hline Ensino Superior & 13 & $\begin{array}{l}\text { BAGNI et al., 2020; BELATO; CARNEIRO; ATHAYDE, 2019; } \\
\text { CANTOR, 2016; CIFUENTES, 2014; CORREIA; SILVA; SOARES, } \\
\text { 2017; LAGOS CÓRTEZ, 2014; COSTA; ROCHA; CADAVID, 2018; } \\
\text { FIOCHI-MARQUES; OLIVEIRA; MELO-SILVA, 2018; HAAS; } \\
\text { CARVALHO, 2018; MARTINS; ROCHA; COSTA, 2020; MIRANDA et } \\
\text { al., 2018; MIRANDA; LORENO; COSTA, 2020; AGUILAR; FLÁNDEZ, } \\
2020\end{array}$ \\
\hline Educação Básica & 10 & $\begin{array}{c}\text { COBAS-ORTIZ; ISACC-NOA; VARGAS-CAPDEVILA, 2015; } \\
\text { CONCEIÇÃO; VAZ, 2020; CORREIA; SOARES, 2020; LAÍÑO et } \\
\text { al., 2019; MACIEL et al., 2017; MELO; SOARES; ROCHA, 2014; } \\
\text { PESERICO; KRAVCHYCHYN; OLIVEIRA, 2015; RASTELLI; } \\
\text { BANDEIRA, 2019; ROCHA; BARTHOLO; MELO, 2011; VERZANI et } \\
\text { al., } 2018\end{array}$ \\
\hline
\end{tabular}

Fonte: Dados da pesquisa

A Educação Básica foi investigada em 23 artigos. A preocupação com este nível de ensino pode se justificar em função das desigualdades sociais presentes na América Latina, que muitas vezes dificultam a conclusão deste nível de ensino por muitos(as) jovens (MARTíNEZ; TRUCCO; PALMA, 2014; ROSSETTI, 2014; PNUD, 2014).

Os artigos que tratam do Ensino Superior se concentram principalmente a partir do ano de 2016. Este achado se encontra em consonância com as pesquisas internacionais, especialmente na Europa e nos Estados Unidos (CONDE et al., 2021; HARRISON et al., 2021; MIRÓ MOYÀ et al., 2018; MORENO; SUBIJANA; CHAMORRO, 2020; SÁNCHEZ-PATO et al., 2021; STAMBULOVA; WYLLEMAN, 2019). O interesse das pesquisas por esse nível de ensino pode se referir também à percepção de que o esporte pode se constituir em via facilitadora de acesso ao Ensino Superior (ALTMANN; REIS, 2013; ANDRES; GOELLNER, 2018; COELHO et al., 2021; MAQUIAVELI et al., 2021; SOUZA; MARTINS, 2018).

O Quadro 7 demonstra as modalidades esportivas investigadas. 
Quadro 7- Modalidades esportivas investigadas nos artigos

\begin{tabular}{|c|c|c|c|}
\hline $\begin{array}{l}\text { Modalidades } \\
\text { esportivas }\end{array}$ & $\begin{array}{l}\mathrm{N}^{\circ} \text { de } \\
\text { artigos }\end{array}$ & Abordadas de forma exclusiva & $\begin{array}{c}\text { Abordada conjuntamente a } \\
\text { outras modalidades esportivas }\end{array}$ \\
\hline Futebol & 14 & $\begin{array}{l}\text { CONCEIÇÃO; VAZ, 2020; } \\
\text { CORREIA; SOARES, 2020; } \\
\text { MELO; SOARES; ROCHA, 2014; } \\
\text { MELO; ROCHA; SILVA, 2016; } \\
\text { MORO; BERTICELLI, 2019; } \\
\text { MURZI; HERBELLA; SUSTAS, } \\
\text { 2020; OLIVEIRA; BALZANO; } \\
\text { MORAIS, 2017; PEDROZA } \\
\text { JÚNIOR et al., 2020; REIS et } \\
\text { al., 2018; ROCHA; BARTHOLO; } \\
\text { MELO, 2011; SOARES et al., } \\
\text { 2011; 2013; VERZANI et al., 2018 }\end{array}$ & CORREIA; SILVA; SOARES, 2017 \\
\hline Atletismo & 4 & $\begin{array}{l}\text { COBAS-ORTIZ; ISACC-NOA; } \\
\text { VARGAS-CAPDEVILA, } 2015\end{array}$ & $\begin{array}{l}\text { CORREIA; SILVA; SOARES, 2017; } \\
\text { FIOCHI-MARQUES; OLIVEIRA; } \\
\text { MELO-SILVA, 2018; MELO; } \\
\text { ROCHA; ROMÃO, } 2020\end{array}$ \\
\hline Basquetebol & 4 & $\begin{array}{l}\text { FOLLE et al., 2016; MACIEL et al., } \\
2017\end{array}$ & $\begin{array}{l}\text { FIOCHI-MARQUES; OLIVEIRA; } \\
\text { MELO-SILVA, 2018; PESERICO; } \\
\text { KRAVCHYCHYN; OLIVEIRA; } \\
2015\end{array}$ \\
\hline Handebol & 3 & ANDRES; GOELLNER, 2018 & $\begin{array}{l}\text { FIOCHI-MARQUES; OLIVEIRA; } \\
\text { MELO-SILVA, 2018; PESERICO; } \\
\text { KRAVCHYCHYN; OLIVEIRA; } \\
2015\end{array}$ \\
\hline Futsal & 2 & SOUZA; MARTINS, 2018 & $\begin{array}{c}\text { PESERICO; KRAVCHYCHYN; } \\
\text { OLIVEIRA, } 2015\end{array}$ \\
\hline Judô & 1 & --- & MELO; ROCHA; ROMÃO, 2020 \\
\hline Natação & 1 & --- & MELO; ROCHA; ROMÃO, 2020 \\
\hline Remo & 1 & AGUILAR; FLÁNDEZ, 2020 & --- \\
\hline Tênis & 1 & --- & BAGNI et al., 2020 \\
\hline Tênis de mesa & 1 & --- & BAGNI et al., 2020 \\
\hline Voleibol & 1 & --- & $\begin{array}{c}\text { PESERICO; KRAVCHYCHYN; } \\
\text { OLIVEIRA, } 2015\end{array}$ \\
\hline
\end{tabular}

Fonte: Dados da pesquisa

O futebol é destacado em 14 estudos. Esta modalidade esportiva tem sido considerada como um meio de mobilidade social de pessoas na sociedade contemporânea (DAMO, 2014; MARQUES et al., 2021; RIAL, 2008), e tornou-se tema de interesse em diversas áreas acadêmicas (HOMRICH, 2013). Na América Latina, o futebol também tem um papel muito importante na vida cultural, ultrapassando os limites do jogo e do produto que se consome (GALEANO, 2002). Pode ser considerado como uma fonte de identidade coletiva nos âmbitos regional, nacional e continental, além de inspiração para produções artísticas e literárias (RINKE, 2007).

No entanto, as reais possibilidades oferecidas pelo futebol são distintas desse imaginário. Os homens encontram um cenário de poucos postos de trabalho, em sua maioria com baixos salários (DAMO, 2007; SOARES et al., 2011), e as mulheres encontram poucas condições estruturais de construir uma carreira profissional (SALVINI; MARCHI JR, 2016). 
As modalidades esportivas podem se relacionar a alguns marcadores sociais, por exemplo, ao analisar os atletas participantes do Programa Bolsa Atleta do Governo Federal brasileiro, os níveis socioeconômicos e de certificação acadêmica das famílias de atletas de judô eram maiores do que o das famílias de atletas do atletismo (MELO; ROCHA; ROMÃO, 2020).

Entre estudantes-atletas homens e mulheres, os primeiros compõem o grupo mais investigado nos artigos analisados. O Quadro 8 indica essa proporcionalidade.

Quadro 8 - Gênero das modalidades investigadas

\begin{tabular}{|c|c|c|}
\hline Gênero & $\begin{array}{c}\mathbf{N}^{\circ} \text { de } \\
\text { artigos }\end{array}$ & Autores(as) \\
\hline Homens & 15 & $\begin{array}{r}\text { BAGNI et al., 2020; CONCEIÇÃO; VAZ, 2020; CORREIA; SOARES, } \\
\text { 2020; FIOCHI-MARQUES; OLIVEIRA; MELO-SILVA, 2018; MELO; } \\
\text { SOARES; ROCHA, 2014; OLIVEIRA; BALZANO; MORAIS, 2017; } \\
\text { MORO; BERTICELLI, 2019; MURZI; HERBELLA; SUSTAS, 2020; } \\
\text { PEDROZA JÚNIOR et al., 2020; REIS et al., 2018; ROCHA; } \\
\text { BARTHOLO; MELO, 2011; SOARES et al., 2011; 2013; VERZANI et } \\
\text { al., 2018 }\end{array}$ \\
\hline Mulheres e & 9 & $\begin{array}{r}\text { CORREIA; SILVA; SOARES, 2017; CORREIA, 2019; LAÍNO et } \\
\text { al., 2019; MACIEL et al., 2017; MELO; ROCHA; ROMÃO, 2020; } \\
\text { MIRANDA et al., 2018; 2020; AGUILAR; FLÁNDEZ, 2020; PESERICO; } \\
\text { KRAVCHYCHYN; OLIVEIRA, 2015 }\end{array}$ \\
\hline Mulheres & 3 & $\begin{array}{r}\text { ANDRES; GOELLNER, 2018; FOLLE et al., 2016; SOUZA; MARTINS, } \\
\text { 2018. }\end{array}$ \\
\hline
\end{tabular}

Fonte: Dados da pesquisa

A presença de mulheres atletas no esporte cresceu nas últimas décadas (COAKLEY, 2017), mas este espaço social ainda se constitui em um universo masculino por excelência, em que essa participação é marcada por relações de desigualdade (ALTMANN; REIS, 2013; GOELLNER, 2007), inclusive com menor legitimação dos feitos esportivos quando comparados aos dos homens (MARIVOET, 2002; OLIVEIRA; ALTMANN; MARQUES, 2019).

\subsection{BARREIRAS E FACILITADORES DA DUPLA CARREIRA ACADÊMICO- ESPORTIVA NA AMÉRICA LATINA}

Entre as principais barreiras enfrentadas pelos(as) estudantes-atletas, destaca-se o tempo gasto entre deslocamentos, cansaço físico, escassez de tempo para tarefas, conflitos de agenda em função de viagens e competições, e ausência de apoio institucionalizado (BAGNI et al., 2020; CONCEIÇÃO; VAZ, 2020; MELO; SOARES; ROCHA, 2014; MELO; ROCHA; ROMÃO, 2020; LAÍÑO et al., 2019; ROCHA; BARTHOLO; MELO, 2011; SOARES et al., 2011; 2013). A carreira esportiva é muitas vezes priorizada especialmente quando existe uma alta expectativa com retornos financeiros (CORREIA; MELO, SOARES, 2020; MELO et al., 2016), nestes casos, se a carreira acadêmica é relegada, são eventos possíveis o abandono ou defasagem escolar (OLIVEIRA; BALZANO; MORAIS, 2017). O mesmo acontece no contexto europeu (GUIROLA GÓMEZ et al., 2018; LÓPEZ-FLORES; HONG; BOTWINA, 
2021; STAMBULOVA; WYLLEMAN, 2019; RYBA et al., 2017; SKRUBBELTRANG et al., 2020).

Artigos que se dedicaram a identificar e/ou analisar leis, políticas públicas e/ou iniciativas institucionais esportivas e/ou acadêmicas, que pudessem contribuir para a conciliação da dupla carreira na América Latina, observaram carência de projetos institucionalizados que organizem as atribuições dos(as) agentes envolvidos(as) no processo. Quando presentes, se demonstraram insuficientes, por vezes contraditórias (AGUILAR; FLÁNDEZ, 2020; CARVALHO; HAAS, 2015; CIFUENTES; 2014; COSTA; ROCHA; CADAVID, 2018; HAAS; CARVALHO, 2018; LAGOS CORTÉS, 2014; MIRANDA; SANTOS; COSTA, 2020; ROCHA et al., 2020).

Ações institucionalizadas pontuais são identificadas e podem oferecer exemplos de boas práticas. No programa denominado "Basquetebol para todos", realizado no Brasil pela Universidade do Estado de Santa Catarina (UDESC), na cidade de Florianópolis, percebeu-se como medida bem-sucedida, reuniões frequentes entre a família dos estudantes-atletas, os(as) treinadores(as) da equipe esportiva e representantes da escola. Os estudantes-atletas participantes no Projeto identificaram receber o suporte das instituições esportiva e acadêmica, sobretudo no equilíbrio de flexibilizações nos momentos de conflito de agendas (MACIEL et al., 2017).

No âmbito do Ensino Superior, em uma pesquisa realizada na Universidad Santo Tomás, na Colômbia, um programa de apoio institucionalizado promoveu uma menor taxa de abandono, melhora na média acadêmica e melhora nos resultados esportivos dos(as) estudantes-atletas. A medida adotada foi identificar o(a) estudanteatleta de nível de elite e oferecer apoios diferenciados daqueles oferecidos aos(às) estudantes-atletas de representação exclusivamente universitária. Essa diferenciação permitiu medidas efetivas, como: tutoria, reuniões periódicas e mediação de acordos com os(as) docentes; tratamento diferenciado na cobrança de tarefas e presenças nas aulas em que atividades remotas pudessem ser oferecidas; e reconhecimento por conquistas esportivas. O Programa exige a contrapartida do(a) estudanteatleta de atingir uma determinada média ponderada e cumprir os acordos e prazos estabelecidos com o(a) tutor(a) e com os(as) docentes (CANTOR, 2016).

Este exemplo colombiano encontra respaldo nas avaliações feitas sobre o Programa Bolsa Atleta da Universidade de Brasília. No caso desta instituição, os(as) estudantes-atletas consideram tão importante quanto o recebimento do auxílio financeiro, o apoio da Universidade em ações de seu cotidiano que favoreçam a conciliação das demandas das duas carreiras (MIRANDA et al., 2018; MIRANDA; LORENO; COSTA, 2020).

Esses ajustes parecem favorecer a manutenção do(a) estudante-atleta na carreira acadêmica. Porém, em situações em que clubes esportivos não se empenham em adequar suas práticas para promover a oportunidade de equilíbrio de dedicação dos(as) jovens estudantes-atletas, tanto ao esporte, quanto aos estudos (LAÍÑO et al., 2019; MELO; ROCHA; SILVA, 2016; MELO; ROCHA; ROMÃO, 2020; MIRANDA; SANTOS; COSTA, 2020; RASTELLI; BANDEIRA, 2019; ROCHA; BARTHOLO; MELO, 2011), esta relação pode construir uma percepção no(a) estudante-atleta de menor importância dos compromissos acadêmicos em relação 
aos esportivos (MORO; BERTICELLI, 2019). Verifica-se que a principal forma de apoio, e muitas vezes a única, quando ocorre, é o oferecimento de bolsas de estudos que são concedidas tanto em parceria com instituições esportivas, como de maneira exclusiva pelas instituições acadêmicas (ALTMANN; REIS, 2013; COELHO et al., 2021; FOLLE et al., 2016; MAQUIAVELI, et al., 2021).

Embora nem sempre haja relatos de ações coordenadas e sistemáticas de suporte aos(às) estudantes-atletas para conciliação da dupla carreira, observa-se nos estudos analisados, especialmente no Brasil, atletas inseridos nas mais variadas modalidades esportivas com níveis de escolarização superiores à população de mesma faixa etária (COELHO et al., 2021; MAQUIAVELI et al., 2021; SOARES et al., 2013; SOUZA; MARTINS, 2018). Na Argentina, em um grande clube de futebol profissional, estudantes-atletas que moram em alojamentos administrados pela instituição têm menores índices de abandono escolar do que os atletas que moram em suas próprias casas (MURZI; HERBELLA; SUSTAS, 2020). Esses resultados indicam uma possível contribuição de instituições esportivas na permanência e conclusão dos estudos dos(as) atletas.

Além disso, o ambiente familiar deve ser considerado como fator importante no desempenho acadêmico de estudantes-atletas (MORET; OHL, 2019), sendo que o acesso à informação e a renda familiar são fatores que podem influenciar a relação do(a) estudante com a escola e a universidade (PIOTTO; NOGUEIRA, 2016). Um maior grau acadêmico alcançado pelos pais e mães pode ser uma referência que reforça positivamente as disposições para o investimento nos estudos (BOURDIEU; PASSERON, 2014). A carreira esportiva, especialmente no futebol brasileiro, pode ser observada como um projeto familiar em que todos se mobilizam para o alcance do sucesso no alto rendimento (ROCHA; BARTHOLO; MELO, 2011, SOARES et al., 2011, CORREIA; SOARES, 2020). O apoio familiar se vincula fortemente às condições socioeconômicas e culturais dos membros da família. Indica-se que quanto melhores são essas condições, mais o projeto familiar favorece a conciliação entre as duas carreiras (CHRISTENSEN; SØRENSEN, 2009; CONDELLO et al., 2019; CORREIA; SOARES, 2020; SHERIDAN; COFFEE; LAVALLEE, 2014).

Dois artigos abordaram os efeitos da dupla carreira no pós-carreira de atletas de futebol no Brasil, um envolvendo atletas que jogaram na seleção brasileira principal (REIS et al., 2018), e outro que atuaram nas principais equipes do estado de Pernambuco, no Brasil (PEDROZA JÚNIOR et al., 2020). Ambos os trabalhos indicaram insucesso na conciliação dos compromissos esportivos e acadêmicos. Isso dificultou a inserção em novas profissões.

As consequências de uma dupla carreira desequilibrada podem afetar tanto o(a) estudante-atleta, como a sociedade de uma forma geral, uma vez que o(a) atleta pode enfrentar dificuldades de inserção em outra atividade quando encerrar a carreira esportiva. Deste modo, a construção da dupla carreira para estudantes-atletas pode ser benéfica se nela estiverem envoltos apoios para situação atual e para as projeções futuras. A preparação e a facilitação da adaptação à carreira pós-esporte proporcionam uma maior segurança, que incluem a inserção em outras atividades sociais (ALFERMANN; STAMBULOVA, 2007; STAMBULOVA; ALFERMAN, 2019). 


\section{CONSIDERAÇÕES FINAIS}

Este estudo descreveu e analisou a produção científica, em formato de artigos, sobre dupla carreira acadêmico-esportiva na América Latina. Assim como identificou a distribuição cronológica e os países de origem das publicações, mapeou a distribuição geográfica dos pesquisadores e suas interações, identificou as abordagens de pesquisa utilizadas, os ambientes e contextos de prática esportiva e grau acadêmico e caracterizou as temáticas e tópicos tratados nos estudos.

As pesquisas sobre dupla carreira acadêmico-esportiva são recentes na América Latina, sendo que o Brasil figura como principal país em termos de publicações e número de pesquisadores(as). Nota-se pouca interação entre os(as) pesquisadores(as) de diferentes países. Predominam as abordagens qualitativas. $\mathrm{O}$ contexto esportivo das categorias de base e o nível de ensino da Educação Básica foram os mais investigados. A partir de 2016, aumentaram os estudos no contexto do esporte universitário e ou de elite e no Ensino Superior. Entre as modalidades esportivas investigadas, predominam as praticadas por homens, especialmente o futebol.

As principais temáticas analisadas permitiram identificar a complexidade das relações que permeiam o(a) estudante-atleta, destacam-se: tensões provocadas pela concorrência do tempo entre as carreiras; tendência à priorização da carreira esportiva; possíveis consequências da priorização esportiva associada ao desprezo pela carreira acadêmica; carência de leis e projetos institucionalizados que organizem as atribuições dos agentes envolvidos no processo de dupla carreira; iniciativas pontuais que exemplificam ações que favorecem a conciliação; a responsabilidade em lidar com as demandas conciliatórias recai muitas vezes sobre o estudante-atleta e sua família; as bolsas de estudo parecem favorecer o acesso ao Nível Superior de ensino; a carreira esportiva se apresenta como um projeto familiar; e o apoio familiar se direciona em função de aspectos socioeconômicos e culturais.

A pesquisa sobre a dupla carreira na América Latina encontra-se em expansão, lacunas que podem ser aprofundadas em futuros estudos foram identificadas. São elas: a ampliação de pesquisas em mais países; a promoção de mais colaboração entre pesquisadores(as) de diferentes países; a diversificação de modalidades esportivas investigadas; mais estudos sobre mulheres esportistas; o aprofundamento das relações de diferentes agentes (família, treinadores(as) esportivos(as), dirigentes esportivos, professores(as) e gestores(as) escolares) e agências (Poder Público, Instituições Esportivas, Instituições Acadêmicas), em diferentes contextos e etapas do processo da dupla carreira; a investigação de leis e programas de diferentes países latino-americanos que apoiem o(a) estudante-atleta; a verificação da qualidade do processo acadêmico experenciado pelos(as) atletas; e o aprofundamento das relações entre as transições esportivas e acadêmicas e suas consequências póscarreira esportiva.

O presente trabalho, limitado pela ausência de análises em livros, teses e dissertações, valoriza as produções científicas sobre a dupla carreira realizadas na América Latina, identifica e analisa o cenário atual e assim pode contribuir para 
ações práticas vinculadas à melhor estruturação das experiências de dupla carreira de estudantes-atletas nesta importante região.

\section{REFERÊNCIAS}

AGUILAR, José Sebastián; FLÁNDEZ, Jorge Guillermo. Identificación de factores obstaculizadores del proceso académico em deportistas federados y de elite en Chile.

Revista Ciencias de la Actividad Física UCM, v. 21, n. 2, p. 1-14, jul./dic. 2020. DOI: http:// doi.org/10.29035/rcaf.21.2.1

ALFERMANN, Dorothee; STAMBULOVA, Natalia. Career transitions and career termination. Handbook of Sport Psychology. 3. ed. New York: John Wiley, 2007. cap. 32, p. 712-733.

ALTMANN, Helena; REIS, Heloisa Helena Baldy. Futsal feminino na América do Sul: trajetórias de enfrentamentos e de conquistas. Movimento (Porto Alegre), v.19, n.3, p.211-232, 2013. DOI: https://doi.org/10.22456/1982-8918.35077

ANDERSSON, Rebecca; BARKER-RUCHTI, Natalie. Career paths of Swedish top-level women soccer players. Soccer and Society, v. 20, n. 6, p.857-871, 2018. DOI: https://doi.or $\mathrm{g} / 10.1080 / 14660970.2018 .1431775$

ANDRES, Suélen de Souza; GOELLNER, Silvana Vilodre. Trajetórias esportivas de jogadoras de handebol e suas narrativas sobre ser profissional da modalidade. Movimento (Porto Alegre), v. 24, n. 2, p. 527-538, abr./jun. 2018. DOI: https://doi.org/10.22456/1982$\underline{8918.79795}$

AZEVEDO, Márcio Faria; SANTOS, Wagner; COSTA, Felipe Rodrigues da; SOARES, Antônio Jorge Gonçalves. Formação escolar e formação esportiva: caminhos apresentados pela produção acadêmica. Movimento (Porto Alegre), v. 23, n. 1, p. 185-200, jan./mar. 2017. DOI: https://doi.org/10.22456/1982-8918.61300

BAGNI, Guilherme; MORÃO, Kauan Galvão; VERZANI, Renato Henrique; MACHADO, Afonso Antonio. Agentes estressores e o enfrentamento de problemas em tenistas e mesatenistas universitários. Caderno de Educação Física e Esporte, Marechal Cândido Rondon, v. 18, n. 2, p. 39-43, maio/ago. 2020. DOI: https://doi.org/10.36453/23185104.2020.v18.n2.p39

BELATO, Ana Kelly de Morais Silva; CARNEIRO, Fernando Henrique Silva; ATHAYDE, Pedro Fernando Avalone de. Análise do programa Bolsa Atleta universitária na Universidade de Brasília de 2011 a 2015. Motrivivência, v. 31, n. 57, p. 01-22, jan, /mar. 2019. DOI: https://doi.org/10.5007/2175-8042.2019e55300

BOURDIEU, Pierre; PASSERON, Jean-Claude. Os herdeiros: os estudantes e a cultura. Florianópolis: Editora da UFSC, 2014.

BRAUN, Virginia; CLARKE, Victoria. Using thematic analysis in Psychology. Qualitative research in Psychology, v. 3 n. 2, p. 77-101, 2006. DOI: https://doi. org/10.1191/1478088706qp063oa

BRAUN, Virginia; CLARKE, Victoria. Reflecting on reflexive thematic analysis. Qualitative Research in Sport, Exercise and Health, v. 11, n. 4, p. 589-597, 2019. DOI: https://doi.org/ 10.1080/2159676X.2019.1628806 
BRAUN, Virginia; CLARKE, Victoria. Thematic Analysis. APA Handbook of Research Methods in Psychology, v. 2, p. 57-71, 2012. DOI: https://doi.org/10.1037/13620-004

CADAVID, Marlon Andrés Amaya; COSTA, Felipe Rodrigues da; CARNEIRO, Felipe Correia Barros. Cobertura de bases de datos científicas sobre el tema de la carrera dual en el deporte. The Journal of the Latin American Socio-cultural Studies of Sport (ALESDE), v. 13, n. 1, p.99-109, 2021. Disponível em: https://revistas.ufpr.br/alesde/article/view/80185. Acesso em: 20 jan. 2022.

CANTOR, Julio César Rueda. Programa de acompañamiento a estudiantes-deportistas: una experiencia exitosa en la Universidad Santo Tomás. Revista Ímpetus, v.10 n. 1-2, p. 25-36, 2016. Disponível em: https://revistas.unillanos.edu.co/index.php/impetus/article/view/407 .

Acesso em: 13 jan. 2022.

CAPUT-JOGUNICA, Romana; ĆURKOVIĆ, Sanja; BJELIĆ, Gordana. Comparitive analysis: support for student-athletes and the guidelines for the universities in southeast Europe.

Sport Science, v. 5, n. 1, p. 21-26, 2012.

CARVALHO, Ricardo Antonio Torrado de; HAAS, Célia Maria. Conflito na legislação brasileira referente à escolarização de seus jovens atletas. Revista de Estudios e Investigación en Psicología y Educación, v. extr., n. 12, p. 11-15, 2015. DOI: https://doi. org/10.17979/reipe.2015.0.12.421

CEPAL - COMISSÃO ECONÔMICA PARA AMERICA LATINA E O CARIBE. Dados e estatísticas do ano de 2018. Disponível em: https://www.cepal.org/pt-br Acesso em: 26 setembro de 2020.

CHASSOT, A. Ciência é masculina? É, sim senhora... Contexto e Educação, v. 19 n. 71/72, p. 9-28, 2004. DOI: https://doi.org/10.21527/2179-1309.2004.71-72.9-28

CHRISTENSEN, Mette Krogh; SØRENSEN, Jan Kahr. Sport or school? Dreams and dilemmas for talented young Danish football players. European Physical Education Review, v. 5, n. 1, p. 115-133, 2009. DOI: https://doi.org/10.1177/1356336X09105214

CIFUENTES, Asceneth Maria Sastre. Propuesta de un programa de acompañamiento a estudiantes deportistas de alto rendimiento: Avances en el compromiso de la Facultad de Cultura Física, Deporte y Recreación de la USTA en la formación profesional de deportistas. Revista Impetus, v.8, n. 2, p. 117-125, 2014. DOI: https://dx.doi.org/10.22579/20114680.120

COAKLEY, Jay. Sports in society: issues and controversies. 2. ed. Saint Louis: Times Mirror/Mosby College, 2017.

COBAS-ORTIZ, Yanelis.; ISACC-NOA, Eusebia.; VARGAS-CAPDEVILA, María Mercedes. La caracterización psicosocial del atleta del deporte Atletismo: Una premisa en la iniciación deportiva. EduSol, v. 15, n. 51, abr./ jun., p. 89-99, 2015.

COELHO, Guilherme Fernandes; MAQUIAVELI, Giulia; VICENTINI, Lucas; RICCI, Christiano Streb; MARQUES, Renato Francisco Rodrigues. Dual career in Brazil: analysis on men elite futsal players' academic degree. Cultura, Ciencia y Deporte, v.16, n.47, p. 69-83, 2021. DOI: https://doi.org/10.12800/ccd.v16i47.1696

COMMISION OF THE EUROPEAN COMMUNITIES. White Paper on Sport. Brussels, 2007.

CONCEIÇÃO, Daniel Machado da; VAZ, Alexandre Fernandez. Concomitância entre estudar e jogar: observações sobre o processo de descontinuidade na escolarização de jogadores de futebol em formação. Revista Eletrônica de Ciências Sociais, n. 31, p. 91-108, 2020. DOI: https://doi.org/10.34019/1981-2140.2020.30510" 
CONDE, Elena; MEROÑO, Lourdes; ARIAS-ESTERO, José Luis; GARCÍA-ROCA, Juan Alfonso; LEIVA-ARCAS, Alejandro; CÁNOVAS-ÁLVAREZ, Francisco José; ISIDORI, Emanuele; SÁNCHEZ-PATO, Antonio. Percepción de la influencia del modelo Estport en la carrera dual de los estudiantes-deportistas en universidades de España e Italia. Cultura, Ciencia y Deporte, v. 16, n. 47, 2021. DOI: https://ccd.ucam.edu/index.php/revista/article/ view/1623

CONDELLO, Giancarlo; CAPRANICA, Laura; DOUPONA, Mojca; VARGA, Kinga; BURK, Verena. Dual-career through the elite university student-athletes' lenses: The international FISU-EAS survey. v.14, n.10, p.223-278, 2019. DOI: https://doi.org/10.1371/journal. pone. 0223278

CORREIA, Carlus Augustus Jourand; MELO, Leonardo Bernardes Silva de; SOARES, Antonio Jorge Gonçalves. Mercado esportivo e escolarização de mulheres atletas. Revista Novos Olhares Sociais. v. 3, n. 1, p. 199-217, 2020. Disponível em: https://www3.ufrb.edu. br/ojs/index.php/novosolharessociais/article/view/506/243 Acesso em: 29 jun. 2021

CORREIA, Carlus Augustus Jourand; SILVA, José Cláudio Sooma; SOARES, Antonio Jorge Gonçalves. Colégio Vasco da Gama: notas para pensar os entrelaçamentos das culturas escolares com as práticas esportivas. Perspectiva, v. 35, n. 1, p. 188-213, jan./mar. 2017. https://doi.org/10.5007/2175-795X.2017v35n1p188

CORREIA, Carlus Augustus Jourand; SOARES, Antonio Jorge Gonçalves. Dilemas da dupla carreira: projeto escolar e futebolístico de estudantes-atletas das classes médias e altas do Rio de Janeiro. Revista Eletrônica de Ciências Sociais, n. 31, p. 51-75, 2020. DOI: https:// doi.org/10.34019/1981-2140.2020.30350

CORTES DÍAZ, José Tomás; GALAK, Eduardo. Trayectoria dual en colombia: un estado de la cuestión entre la legislación, educación y competición. The Journal of the Latin American Socio-cultural Studies of Sport (ALESDE), v. 13, n. 1, p. 17-38, 2021. Disponível em: https://revistas.ufpr.br/alesde/article/view/77684. Acesso em: 20 jan. 2022.

COSTA, Felipe Rodrigues da; ROCHA, Hugo Paula Almeida da; CADAVID, Marlon Andrés Amaya. Temas em Educação Física Escolar, v. 3, n. 1, p. 1-6, out. 2018. DOI: http:// dx.doi.org/10.33025/tefe.v3i1.1910

DAMO, Arlei Santos. Do dom à profissão: a formação de futebolistas no Brasil e na França. São Paulo: Hucitec, 2007.

DAMO, Arlei Santos. Training soccer players in Brazil. Soccer and Society, v. 15, n. 1, p. 93-107, 2014.

ESTÉBANEZ, María Elina. As mulheres na ciência regional: diagnóstico e estratégias para a igualdade. Revista ConCiência, 2003. Disponível em: DOI: http://www.comciencia.br/ reportagens/mulheres/10.shtml.

EUROPEAN COMMISSION. EU guidelines on dual careers of athletes: recommended policy actions in support of dual careers in high-performance sport. Brussels: Sport Unit, European Commission, Education, Culture and Sport. 2012. Disponível em: http:// ec.europa.eu/assets/eac/sport/library/documents/dual-career-guidelines-final en.pdf. Acesso em: 4 de outubro de 2020.

FIOCHI-MARQUES, Manoella; OLIVEIRA, Marina Cardoso; MELO-SILVA, Lucy Leal. Construção da carreira do universitário-atleta: percepções e expectativas na transição universidade-trabalho. Psicologia Revista, v. 27, n. esp., p. 679-706, 2018. DOI: https://doi. org/10.23925/2594-3871.2018v27i3p679-706 
FOLLE, Alexandra et al. Transições no processo de desenvolvimento de atletas do basquetebol feminino. Revista Brasileira de Educação Física e Esporte, v. 30, n. 2, p. 477-490, 2016. DOI: https://doi.org/10.1590/1807-55092016000200477.

GALEANO, Eduardo Futebol ao sol e sombra. Porto Alegre: L\&PM, 2002.

GLÄNZEL, Wolfgang; SCHUBERT, András. Analysing scientific networks through coauthorship. In: MOED H.F.; GLÄNZEL W.; SCHMOCH U. (eds). Handbook of quantitative science and technology research. Springer, Dordrecht, 2005. p. 257-276.

GOELLNER, Silvana Vilodre. Feminismos, mulheres e esportes: questões epistemológicas sobre o fazer historiográfico. Movimento (Porto Alegre), v. 13, n. 2, 171-196, 2007. DOI: https://doi.org/10.22456/1982-8918.3554

GUIDOTTI, Flavia; CORTIS, Cristina; CAPRANICA, Laura. Dual career of European studentathletes: a systematic literature review. Kinesiologia Slovenica, v. 21, n. 3, p. 5-20, 2015. Disponível em: https://edu.empatiasport.eu/wp-content/uploads/2020/11/2015-systematicliterature-review-on-dual-career-Guidotti-et-al.pdf . Acesso em: 13 jan. 2022.

GUIROLA GÓMEZ, Ivan; TORREGROSA, Miquel; RAMIS, Yago.; JAENES, José Carlos. Remando contracorriente: facilitadores y barreras para compaginar el deporte y los estudios. Revista Andaluza de Medicina Del Deporte, v.11, n.1, p.12-17, 2018. DOI: https://doi. org/10.1016/j.ramd.2016.08.002

HAAS, Maria Célia; CARVALHO, Ricardo Antonio Torrado de. Escolarização dos talentos esportivos: busca pelo sucesso no esporte, distanciamento da escola e conflitos legais. Revista @mbienteeducação, v. 11, n. 3, p. 374-394 set/dez. 2018. https://doi.org/10.26843/ ae19828632v11n32018p374a394

HARRISON, Carlton Keith; PROCTOR, Larry; SETH, Pyar; MARTIN, Brandon; BUKSTEIN, Scott J.; HARRISON JR, Otis C. The 2020 nfl draft: dual-career (dc) messaging on education, families, gender, and race under American capitalismo. Alesde, v.13, n.1, p. 150180, 2021.

HODKINSON, Phil; BIESTA, Gert; JAMES, David. Understanding learning cultures. Educational Review. v. 59, n. 4, p. 415-427, 2007. DOI: https://doi. org/10.1080/00131910701619316

HODKINSON, Phil; SPARKES, Andrew C. Careership: A sociological theory of career decision making. British Journal of Sociology of Education, v. 18, n. 1, p. 29-44, 1997. DOI: http://www.jstor.org/stable/1393076

HOMRICH, Carlos Augusto; SOUZA, Júlio Cesar. Para além da questão técnica do ensinar/ aprender futebol: outras possibilidades. In: KUNZ, Eleonor. Didática da educação física 3: futebol. 3. ed. ljuí: Unijuí. 2013. p. 41-86.

IPEA. Instituto de Pesquisa Econômico Aplicada. O que é? - Índice de Gini. 2004. Disponível em https://www.ipea.gov.br/desafios/index. Acesso em 17 jan. 2022.

LAGOS CORTÉS, Diogenes. Estrategias de las universidades colombianas para favorecer el acceso, permanencia y finalización de estudios en deportistas de alto rendimento. Lúdica Pedagógica, n. 19, p. 77-89, 2014. https://doi.org/10.17227/01214128.19ludica77.89

LAíÑO, Fernando Alberto; TUÑÓN, lanina; CASTRO, Hernán; PÉREZ RODRÍGUEZ, Martín. Educacion formal y deporte de élite en adolescentes argentinos. Educación Física y Ciencia, v. 21, n. 3, e089, p. 1-14, jul./sep. 2019. Disponível em: https://dialnet.unirioja.es/ servlet/articulo?codigo=7350855 Acesso em: 29 jun. 2021 
LATIN AMERICA UNIVERSITY RANKINGS 2021. The World University Rankings.

Disponível em: https://www.timeshighereducation.com/world-university-rankings/2021/latinamerica-university-rankings\#! Acesso em: 17 jul. 2021.

LINNÉR, Lukas; STAMBULOVA, Natalia. B.; LINDAHL, Kent; WYLLEMAN, Paul. Swedish university student-athletes' dual career scenarios and competences. International Journal of Sport and Exercise Psychology, p. 1-16, 2019. https://doi.org/10.1080/161219 $\underline{\text { 7X.2019.1611898 }}$

LÓPEZ-FLORES, Marcos; HONG, Hee Jung; BOTWINA, Grzegorz. Dual career of junior athletes: Identifying challenges, available resources, and roles of social support providers. Cultura, Ciencia y Deporte, v. 16, n. 47, p. 117-129, 2021. https://doi.org/10.12800/ccd. $\underline{\mathrm{v} 16 \mathrm{i} 47.1673}$

MACIEL, Larissa Fernanda Porto; FOLLE, Alexandra; SOUZA, Paulo Henrique Xavier de; VAZ, Gilberto; SALLES, William das Neves. Envolvimento esportivo e escolar: percepções de alunos-atletas do programa "Basquetebol Para Todos". Revista Brasileira Ciência e Movimento, v. 25, n. 4, p. 92-103, 2017. Disponível em: https://portalrevistas.ucb.br/index. php/RBCM/article/view/7776 . Acesso em: 13 jan. 2022.

MAQUIAVELI, Giulia; COELHO, Guilherme Fernandez; VICENTINI, Lucas; OLIVEIRA, Flavia Volta Cortes; RICCI, Christiano Streb; MARQUES, Renato Francisco Rodrigues. O desafio da dupla carreira: análise sobre os graus acadêmicos de atletas de elite do futsal feminino brasileiro. Journal of the Latin American socio-cultural studies of sport, v. 12, n. 1, p., 2021. Disponível em: https://revistas.ufpr.br/alesde/article/view/80417 Acesso em: 13 jan. 2022.

MARIVOET, Salomé. Aspectos sociológicos do desporto. 2. ed. Lisboa: Livros Horizonte, 2002.

MARQUES, Renato Francisco Rodrigues; SCHUBRING, Astrid.; BARKER-RUCHTI, Natalie; NUNOMURA, Myrian; MENEZES, Rafael Pombo. From soccer to futsal: Brazilian elite level men players' career pathways. Soccer \& Society, v. 22, n. 5, p. 486-501, 2021. DOI: https:// doi.org/10.1080/14660970.2020.1826936

MARTÍNEZ, Rodrigo; TRUCCO, Daniela; PALMA, Amalia. El analfabetismo funcional en América Latina y el Caribe: Panorama y principales desafíos de política. CEPAL - Serie Políticas Sociales, n.198, p.1-41, 2014.

MARTINS, Fernando B; ROCHA, Hugo Paula A; COSTA, Felipe da. A narrative review on student- athletes in higher education. Revista Internacional de Educação Superior, v. 6, 2020. DOI: https://doi.org/10.20396/riesup.v6i0.8657154

MARTINS, Mariana Zuaneti et al. AS MULHERES E A DUPLA CARREIRA: LINHAS TÊNUES ENTRE A CONCILIAÇÃO E O ABANDONO ESPORTIVO. The Journal of the Latin American Socio-cultural Studies of Sport (ALESDE), v. 13, n. 1, p. 110-132, 2021. Disponível em: https://revistas.ufpr.br/alesde/article/view/76885. Acesso em 20 jan. 2022.

MATEU, Pau; INGLÉS, Eduard; TORREGROSSA, Miquel.; MARQUES, Renato Francisco Rodrigues; STAMBULOVA, Natalia.; VILANOVA, Ana. Living life through sport: the transition of elite Spanish student-athletes to a university degree in physical activity and sports sciences. Frontiers in Psychology, v.11, p. 1367, 2020. DOI: https://doi.org/10.3389/ fpsyg.2020.01367

MATEU, Pau; VILANOVA, Ana; INGLÉS, Eduard. Análisis de las características organizativas de los programas de apoyo a estudiantes-deportistas de élite en el sistema universitario de Cataluña. Movimento (Porto Alegre), v.24, n.4, p.1205-1218, 2018. DOI: https://doi.org/10.22456/1982-8918.82235 
MATTEI, Lauro. Trajetória e atualidade da desigualdade na América Latina. Rebela, v. 7, n. 2, p. 242-261, maio/ago. 2017.

MELO, Leonardo Bernardes Silva de; ROCHA, Hugo Paula Almeida da; ROMÃO, Marcio Gabriel; SANTOS, Wagner dos; SOARES, Antonio Jorge Gonçalves. Dupla carreira: dilemas entre esporte e escola. Journal of Physical Education, v. 31, p. 1-13, 2020. DOI: https:// doi.org/10.4025/iphyseduc.v31i1.3145

MELO, Leonardo Bernardes Silva de; ROCHA, Hugo Paula Almeida da; SILVA, André Luiz da Costa; SOARES, Antônio Jorge Gonçalves. Jornada escola versus tempo de treinamento: a profissionalização no futebol e a formação na escola básica. Revista Brasileira de Ciência do Esporte, v. 38, n. 4, p. 400-406, out./dez. 2016. Disponível em: http://www.redalyc.org/articulo.oa?id=401348355014 Acesso em: 29 jun. 2021.

MELO, Leonardo Bernardes Silva de; SOARES, Antônio Jorge Gonçalves; ROCHA, Hugo Paula Almeida da. Perfil educacional de atletas em formação no futebol no Estado do Rio de Janeiro. Revista Brasileira de Educação Física e Esporte, v. 28, n. 4, p. 617-628, out./ dez. 2014. DOI: https://doi.org/10.1590/1807-55092014000400617

MIRANDA, luri Scremin de; LORENO, Leonardo Tavares Corado; COSTA, Felipe Rodrigues da. A dupla jornada do atleta universitário: perspectivas para a conciliação entre estudos e treinos na Universidade de Brasília. Movimento (Porto Alegre), v. 26, p. e26059, 2020. DOI: https://doi.org/10.22456/1982-8918.100344

MIRANDA, luri Scremin de; SANTOS, Wagner dos; COSTA, Felipe Rodrigues da. Dupla carreira de estudantes atletas: uma revisão sistemática nacional. Motrivivência, v. 32, n. 61, p. 01-21, jan./mar. 2020. DOI: https://doi.org/10.5007/2175-8042.2020e61788

MIRANDA luri Scremin; MARTINS, Fernando Bernardes; SILVA, Pedro Romualdo da; COSTA, Felipe Rodrigues da. Dupla jornada no esporte de representação: o caso dos atletas da Universidade de Brasília. Temas em Educação Física Escolar, v. 3, n. 1, p. 1935, out. 2018. DOI: http://dx.doi.org/10.33025/tefe.v3i1.2087

MIRÓ MOYÀ, Salvador Lluís; PÉREZ-RIVASĖS, Andrea; RAMIS LALOUX, Yago; TORREGROSSA, Miquel. ¿Compaginar o elegir?: La transición del bachillerato a la universidad de deportistas de alto rendimiento. Revista de Psicología Del Deporte, v.27, n.2, p.59-68, 2018.

MORENO, Rubén; SUBIJANA, Cristina López de; CHAMORRO, J. L. "I never thought l'd drop out of school". the influence of parents academic history in the development of dual career in the elite athletes. Revista de Psicología Del Deporte, v.29, n.2, p.17-26, 2020.

MORET, Orlan; OHL, Fabien. Social class, the elite hockey player career and educational paths. International Review for the Sociology of Sport, v.54, n.8, p.899-920, 2019. DOI: https://doi.org/10.1177/1012690218765759

MORO, Eduarda; BERTICELLI, Ireno Antônio. Jovens-pobres-jogadores de futebol e suas possibilidades escolares: uma cartografia da educação escolar dos jogadores das categorias de base do futebol brasileiro. Revista Educação Popular, v. 18, n.1, p. 122-139, jan./abr. 2019. DOI: https://doi.org/10.14393/REP-v18n12019-45771

MORRIS Robert; CARTIGNY, Emily; RYBA, Tatiana V.; WYLLEMAN, Paul; HENRIKSEN, Kristoffer; TORREGROSSA, Miquel; LINDAHL, Kent; ERPIČ, Sasa Cecic. A taxonomy of dual career development environments in European countries, European Sport Management Quarterly, v. 21, n. 1, p. 134-151, 2020. DOI: https://doi.org/10.1080/1618474 $\underline{2.2020 .1725778}$ 
MURZI, Diego; HERBELLA, Juan M.; SUSTAS, Sebastián. Ser futbolista juvenil en Argentina. Orígenes, escolarización, vivienda, sentimientos y expectativas de los deportistas en formación de un club de fútbol profesional. Revista Dilemas Contemporáneos: Educación, Política y Valores, v. 8, n. 1, art. 75, 2020.

OLIVEIRA, Edilson Medeiros de; BALZANO, Otávio Nogueira; MORAIS, Pedro Henrique Nascimento. O perfil dos atletas em transição para a fase profissional das equipes de futebol da cidade de Fortaleza e a relação escola e futebol. Revista Brasileira de Futsal e Futebol, v. 9, n. 33, p. 130-137, maio/ago. 2017. Disponível em: http://www.rbff.com.br/ index.php/rbff/article/view/469. Acesso em: 29 jun. 2021.

OLIVEIRA, Flavia Volta Cortes; ALTMANN, Helena; MARQUES, Renato Francisco Rodrigues. The women inclusion on rugby: perceptions of Brazilian national team players. Motriz: revista de educação física, v. 25, n. 3, 2019. DOI: https://doi.org/10.1590/S1980$\underline{6574201900030005}$

PEDROZA JÚNIOR, Edvaldo Torres et al. História de vida de ex-jogadores profissionais de futebol em Pernambuco: formação acadêmica versus formação esportiva. Movimento (Porto Alegre), v. 26, p. e26067, set. 2020. DOl:https://doi.org/10.22456/1982-8918.102789

PESERICO, Cecília Segabinazi; KRAVCHYCHYN, Claudio; OLIVEIRA, Amauri Aparecido Bássoli de. Análise da relação entre esporte e desempenho escolar: um estudo de caso. Pensar a Prática, v. 18, n. 2, abr./jun. 2015. DOI: https://doi.org/10.5216/rpp.v18i2.27965

PIOTTO, Débora Cristina; NOGUEIRA, Maria Alice. Incluindo quem? Um exame de indicadores socioeconômicos do Programa de Inclusão Social da USP. Educação e Pesquisa, v. 42, n. 3, p. 625-649, 2016. DOI: https://doi.org/10.1590/S1517$\underline{9702201609134896}$

PNUD - PROGRAMA DAS NAÇÕES UNIDAS PARA O DESENVOLVIMENTO. Ranking IDH Global 2014: Relatório do Desenvolvimento Humano, 2014. Disponível em: https://www. br.undp.org/content/brazil/pt/home/idh0/rankings/idh-global.html Acesso em: 25 ago. 2020.

RASTELLI, Giovana; BANDEIRA, Alexsandra da Silva."E aí? Como vai a escola?”: uma revisão sistemática sobre o papel da formação esportiva no processo de escolarização de atletas adolescentes. Pensar a Prática, v. 22, p. 1-15, 2019. DOI: https://doi.org/10.5216/ rpp.v22.54863

REIS, Cleiton P. et al. Como ocorreu o processo de término da carreira esportiva de exatletas de futebol que disputaram Copas do Mundo pelo Brasil entre 1966 e 1982 ? Pensar a Prática, v. 21, n. 2, 2018. https://doi.org/10.5216/rpp.v21i2.46829

RIAL, Carmen Silvia. Rodar: a circulação dos jogadores de futebol brasileiros no exterior. Horizontes Antropológicos, v. 14, n. 30, p. 21-65, 2008.

RINKE, Stefan. ¿La última pasión verdadera? Historia del fútbol en América Latina en el contexto global. IBEROAMERICANA. América Latina, v. 7, n. 27, p. 85-100, 2007. DOI: https://doi.org/10.18441/ibam.7.2007.27.85-100

ROCHA, Hugo Paula Almeida da; BARTHOLO, Tiago Lisboa; MELO, Leonardo Bernardes Silva de; SOARES, Antonio Jorge Gonçalves. Jovens esportistas: profissionalização no futebol e a formação na escola. Motriz, v. 17, n. 2, p. 252-263, abr./jun. 2011. Disponível em: https://www.scielo.br/j/motriz/a/rp7hv5GRKwffLfSSX7DphGg/?format=pdf\&lang=pt. Acesso em: 14 jan. 2022. 
ROCHA, Hugo Paula Almeida da; MIRANDA, luri Scremin; COSTA E SILVA, André Luiz; COSTA, Felipe Rodrigues da. A dupla carreira esportiva no Brasil : um panorama na agenda das políticas públicas. Revista Com Censo: Estudos Educacionais Do Distrito Federal, v. 7, n. 2, p. 52-59, 2020. Disponível em: http://www.periodicos.se.df.gov.br/index.php/ comcenso/article/view/848 . Acesso em: 29 jun. 2021.

ROSSETTI, Magdalena. La segregación escolar como um elemento clave en la reproducción de la desigualdad. CEPAL - Serie Políticas Sociales, n. 199, p. 1-64, 2014.

RYBA, Tatiana V.; STAMBULOVA, Natalia; SELÄNNE, Harri; AUNOLA, Kaisa; NURMI, JariErik. "Sport has always been first for me" but "all my free time is spent doing homework": Dual career styles in late adolescence. Psychology of Sport and Exercise, v.33, p.131140, 2017. https://doi.org/10.1016/j.psychsport.2017.08.011

SALVINI, Leila; MARCHI JÚNIOR, Wanderley. "Guerreiras de chuteiras" na luta pelo reconhecimento: relatos acerca do preconceito no futebol feminino brasileiro. Revista Brasileira de Educação Física e Esporte, v. 30, n. 2, 2016. http://dx.doi.org/10.1590/1807$\underline{55092016000200303}$

SÁNCHEZ PATO, Antonio; CONDE PASCUAL, Elena; MEROÑO, Lourdes; ARIAS ESTERO, José Luis; GARCÍA ROCA, Juan Alfonso. Estudio del éxito académico de un modelo universitaro de carrera dual en deportistas -estudiantes según género, nivel de estudios y deporte. Revista Española de Educación Física y Deportes, v. 421, p.35-47, 2018.

SANTOS, Celso Bilynkievycz dos; PILATTI, Luiz Alberto; PEDROSO, Bruno; CARVALHO, Deborah Ribeiro; GUIMARÃES, Alaine Margarete. Previsão do Índice de Desenvolvimento Humano e da expectativa de vida nos países da América Latina por meio de técnicas de mineração de dados. Ciências \& Saúde coletiva, v. 23, n. 11, p. 3745-3756, 2018. DOI: https://doi.org/10.1590/1413-812320182311.26142016

SHERIDAN, Daragh, COFFEE, Pete; LAVALLEE, David. A systematic review of social support in youth sport. International Review of Sport and Exercise Psychology, v. 7, n. 1, p.198-228, 2014. DOI: https://doi.org/10.1080/1750984X.2014.931999

SILVA, Fabiane Ferreira da. Mulheres na ciência: Vozes, tempos, lugares e trajetórias. Dissertação (Mestrado em Educação em Ciências: Química da Vida e Saúde) Universidade Federal do Rio Grande, Rio Grande/RS, 2012.

SKRUBBELTRANG, Lotte Stausgaard; KAREN, David; NIELSEN, Jens Christian; OLESEN, Jesper Stilling. Reproduction and opportunity: A study of dual career, aspirations and elite sports in Danish Sports Classes. International Review for the Sociology of Sport. v. 55, n. 1, p. 38-59, 2020. DOI: https://doi.org/10.1177/1012690218789037

SOARES, Antonio Jorge Gonçalves; MELO, Leonardo Bernardes Silva de; BARTHOLO, Thiago Lisboa; VELARDE, Luis Guilherme Coca; RIBEIRO, Carlos Henrique de Vasconcellos; SANTOS, Tony Meireles dos. Tiempo para el futbol y la escuela: un análisis de los jóvenes jugadores brasileños de Rio de Janeiro. Estudios Sociológicos, v. 31, n. 92, p. 437-469, 2013. Disponível em: http://www.redalyc.org/articulo.oa?id=59831908005 Acesso em: 29 jun. 2021

SOARES, Antonio Jorge Gonçalves; MELO, Leonardo Bernardes Silva de; COSTA, Felipe Rodrigues da; BARTHOLO, Thiago Lisboa; BENTO, Jorge Olímpio. Jogadores de futebol no Brasil: mercado, formação de atletas e escola. Revista Brasileira de Ciências do Esporte, v. 33, n. 4, p. 905-921, out./dez. 2011. Disponível em: http://revista.cbce.org.br/index.php/ RBCE/article/view/902 Acesso em: 29 jun.2021 
SOUZA, Ana Claudia Ferreira de; MARTINS, Mariana Zuaneti. O paradoxo da profissionalização do futsal feminino no Brasil: entre o esporte e outra carreira. Pensar a Prática, v. 21, n. 1, jan./mar. 2018. DOI: https://doi.org/10.5216/rpp.v21i1.45075

STAMBULOVA, Natalia. B; WYLLEMAN, P. Dual career development and transitions. Psychology of Sport and Exercise, v. 21, p. 1-3, 2015. DOI: https://doi.org/10.1016/j. psychsport.2015.05.003

STAMBULOVA, Natalia B; WYLLEMAN, Paul. Psychology of athletes' dual careers: a stateof-the-art critical review of the European discourse. Psychology of Sport \& Exercise, v. 42, p. 74-88, 2019. https://doi.org/10.1016/j.psychsport.2018.11.013

TONG, Allison; FLEMMING, Kate; MCINNES, Elizabeth; OLIVER, Sandy; CRAIG, Jonathan. Enhancing transparency in reporting the synthesis of qualitative research: ENTREQ. BMC Medical Research Methodology, v. 12, n. 181, p. 1-8, 2012. DOI: https://doi. org/10.1186/1471-2288-12-181

VERZANI, Renato Henrique Verzani; MORÃO, Kauan Galvão; BAGNI, Guilherme; MACHADO, Afonso Antonio; SERAPIÃO, Adriane Beatriz de Souza. Desafios da dupla carreira na formação de futebolistas: olhar sobre a escolaridade. Arquivo Ciência Esporte, v. 6 n. 3, p. 110-113, 2018. https://doi.org/10.17648/aces.v6n3.2402 
Abstract: This study analyzed the scientific production on academic-sports dual career in articles from Latin America published in academic journals between the years 2000 and 2020. The selection and analysis of articles followed the ENTREQ, Reflective Thematic Analysis, and Analysis of Social Networks. Eight databases were searched and 39 articles were selected. The results indicated: a) the first articles found date from 2011; b) the studies are mainly concentrated in Brazil; c) the interaction between Latin American researchers is small; d) qualitative approaches predominate; e) Youth sport and Basic Education are the most investigated contexts; f) studies with sports practiced by men, especially football, predominate. It is concluded that the themes analyzed in this work present an overview of academic production in articles on academic-sports dual career in Latin America, while highlighting important gaps to be filled by future studies.

Keywords: Scientific Publication indicators. Athletes. Sports. Researchers.

Resumen: Este estudio analizó la producción científica sobre carrera dual académico-deportiva en artículos de América Latina publicados en revistas académicas entre los años 2000 y 2020. La selección y análisis de los artículos siguió el método/protocolo ENTREQ, Análisis Temático Reflexivo y Análisis de Redes Sociales. Se realizaron búsquedas en ocho bases de datos y se seleccionaron 39 artículos. Los resultados indican: a) los primeros trabajos encontrados son de 2011; b) los estudios se concentran principalmente en Brasil; c) la interacción entre investigadores latinoamericanos es escasa; d) predominan los enfoques cualitativos; e) las categorías de base y la Educación Básica son los contextos más investigados; f) predominan los estudios con modalidades deportivas practicadas por hombres, especialmente el fútbol. Se concluye que los temas analizados en este trabajo presentan un panorama sobre la producción académica en artículos sobre la carrera dual académico-deportiva en América Latina, al mismo tiempo en que destacan importantes vacíos a ser cubiertos por estudios futuros.

Palabras clave: Indicadores de producción científica. Atletas. Deportes. Investigadores. 


\section{(10 MOVIMENTO

NOTAS

\section{LICENÇA DE USO}

Este é um artigo publicado em acesso aberto (Open Access) sob a licença Creative Commons Atribuição 4.0 Internacional (CC BY 4.0), que permite uso, distribuição e reprodução em qualquer meio, desde que o trabalho original seja corretamente citado. Mais informações em: https://creativecommons.org/licenses/by/4.0

\section{CONFLITO DE INTERESSES}

Os autores declararam que não existe nenhum conflito de interesses neste trabalho.

\section{CONTRIBUIÇÕES AUTORAIS}

Christiano Streb Ricci: Conceitualização; Análise Formal; Investigação; Metodologia; Visualização; Redação: rascunho original; Redação: revisão e edição. Rodrigo Aquino: Conceitualização; Análise Formal; Investigação; Metodologia; Supervisão; Redação: revisão e edição.

Renato Francisco Rodrigues Marques: Conceitualização; Análise Formal; Metodologia; Administração do projeto; Supervisão; Redação: revisão e edição.

\section{FINANCIAMENTO}

O presente trabalho foi realizado sem o apoio de fontes financiadoras.

\section{COMO REFERENCIAR}

RICCI, Christiano Streb; AQUINO, Rodrigo; MARQUES, Renato Francisco Rodrigues. A dupla carreira acadêmica-esportiva na América Latina entre os anos 2000 e 2020: análise sobre a produção científica publicada em artigos. Movimento, v.28, p. e28005, jan./dez. 2022. DOI: https://doi.org/10.22456/19828918.117028. Disponível em: https://seer.ufrgs.br/Movimento/article/view/117028. Acesso em: [dia] [mês abreviado]. [ano].

\section{RESPONSABILIDADE EDITORIAL}

Alex Branco Fraga*, Elisandro Schultz Wittizorecki*, Ivone Job*, Mauro Myskiw*, Raquel da Silveira*

*Universidade Federal do Rio Grande do Sul, Escola de Educação Física, Fisioterapia e Dança, Porto Alegre, RS, Brasil. 
Apêndice 1 - Domínios, itens e descritores do Protocolo ENTREQ.

\begin{tabular}{|c|c|c|}
\hline Domínios & Número / Item & Descritores \\
\hline \multirow{2}{*}{$\begin{array}{l}\text { I. Introdução, II. } \\
\text { Métodos e Metodologia }\end{array}$} & 1. Objetivo & Indicar a questão de pesquisa que a síntese aborda \\
\hline & 2. Metodologia de síntese & $\begin{array}{l}\text { Identificar a metodologia ou estrutura teórica que sustenta a síntese e descreva a lógica para a escolha da metodologia (por exemplo, metaetnografia, síntese temática, síntese } \\
\text { interpretativa crítica, síntese teórica fundamentada, sintese realista, meta-agregação, metaestudo, síntese de estruturas). }\end{array}$ \\
\hline \multirow{6}{*}{$\begin{array}{l}\text { III. Pesquisa e seleção } \\
\text { de literatura }\end{array}$} & 3. Abordagem para a busca & $\begin{array}{l}\text { Indicar se a pesquisa foi pré-planejada (estratégias abrangentes de busca para encontrar todos os estudos disponiveis) ou iterativa (para encontrar todos os conceitos } \\
\text { disponiveis até que a saturação teórica seja alcançada). }\end{array}$ \\
\hline & 4. Critérios de inclusão & Especificar os critérios de inclusão/exclusão (por exemplo, em termos de população, idioma, limites de ano, tipo de publicação, tipo de estudo). \\
\hline & \multirow[t]{2}{*}{ 5. Fontes de dados } & Descrever as fontes de informação utilizadas. \\
\hline & & Fornecer a justificativa para o uso das fontes de dados. \\
\hline & 6. Estratégia de Busca Eletrônica & Descrever a pesquisa: estratégias de pesquisa e seus limites. \\
\hline & 7. Estudar métodos de triagem & Descrever o processo de triagem e peneiração do estudo. \\
\hline \multirow{6}{*}{ IV. Avaliação } & 8. Caracteristicas do estudo & Apresentar as características dos estudos. \\
\hline & 9. Resultados da seleção do estudo & Identificar o número de estudos selecionados e fornecer razões para a inclusão e a exclusão dos estudos, indicada em um fluxograma/figura. \\
\hline & 10. Racionalidade para avaliação & Descrever a lógica e a abordagem utilizadas para avaliar os estudos incluídos. \\
\hline & 11. Itens de avaliação & $\begin{array}{l}\text { Apresentar as ferramentas, estruturas e critérios utilizados para avaliar os estudos (por exemplo, ferramentas existentes: CASP, QARI, COREQ)6. Descrever os domínios } \\
\text { avaliados: equipe de pesquisa, desenho do estudo, análise de dados, relatórios e interpretaçöes. }\end{array}$ \\
\hline & 12. Processo de avaliação & Indicar se a avaliação foi conduzida de forma independente por mais de um revisor e se foi necessário consenso. \\
\hline & 13.Resultados de avaliação & Apresentar resultados da avaliação da qualidade e indicar quais artigos, se houver, foram ponderados/excluídos. \\
\hline \multirow{4}{*}{$\begin{array}{l}\text { II. Métodos e } \\
\text { Metodologia }\end{array}$} & 14. Extração de dados & Indicar quais seções dos estudos primários foram analisadas e como foram extraídos os dados dos estudos primários. \\
\hline & 15. Software & Indicar o software de computador usado, se houver. \\
\hline & 16. Número de revisores & Identificar quem estava envolvido na codificação e análise. \\
\hline & 19. Derivação de temas & Explicar se o processo de derivação dos temas ou construções foi indutivo ou dedutivo. \\
\hline \multirow{2}{*}{$\begin{array}{l}\text { V. Síntese dos } \\
\text { resultados }\end{array}$} & 20. Citaçōes/Mençōes & Fornecer citações dos estudos primários para ilustrar temas/construções. \\
\hline & 21. Produção de sintese & Apresentar resultados ricos, atraentes e úteis que vão além de um resumo dos estudos primários. \\
\hline
\end{tabular}

Fonte: Adaptado de Tong et al. (2012)

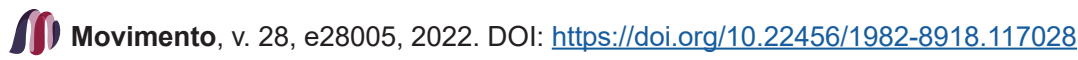


Apêndice 2 - Quadro com as características detalhadas dos artigos analisados

\begin{tabular}{|c|c|c|c|c|c|c|c|c|c|c|c|c|}
\hline \begin{tabular}{|c|} 
País de \\
origem do \\
artigo
\end{tabular} & $\begin{array}{l}\text { Idioma } \\
\text { de } \\
\text { difusão }{ }^{8}\end{array}$ & Ano & Autores & Títulos dos artigos & Periódicos ${ }^{9}$ & Objetivo & Método ${ }^{10}$ & $\begin{array}{l}\text { Modalidades } \\
\text { esportivas }\end{array}$ & Gênero"1 & $\begin{array}{c}\text { Contexto } \\
\text { esportivo }{ }^{12}\end{array}$ & $\begin{array}{c}\text { Contexto } \\
\text { acadêmico }{ }^{13}\end{array}$ & Principais resultados \\
\hline BRA & POR & 2011 & Soares, et al. & $\begin{array}{l}\begin{array}{c}\text { Jogadores de futebol } \\
\text { no Brasil: mercado, } \\
\text { formação de atletas } \\
\text { e escola }\end{array} \\
\end{array}$ & RBCE (Brasil) & \begin{tabular}{|c|} 
Refletir sobre a \\
relação entre a \\
profissionalização no \\
futebol e a escolarização \\
\end{tabular} & RE & Futebol & M & CB & EB e ES & $\begin{array}{l}\text { O futebol se configura em um tipo de negócio } \\
\text { que sustenta uma indústria de formação } \\
\text { profissional que pode estar em competição com a } \\
\text { escolarização. }\end{array}$ \\
\hline BRA & POR & 2011 & $\begin{array}{c}\text { Rocha; } \\
\text { Bartholo; Melo }\end{array}$ & $\begin{array}{l}\text { Jovens Esportistas: } \\
\text { profissionalização no } \\
\text { futebol e a formação } \\
\text { na escola }\end{array}$ & Motriz (Brasil) & \begin{tabular}{|c|} 
Verificar como os atletas \\
das categorias de base \\
do futebol conciliam \\
sua rotina de esportiva \\
e acadêmica; e qual o \\
significado da escola \\
na busca por uma \\
ocupação futura
\end{tabular} & QL & Futebol & M & $\mathrm{CB}$ & EB & $\begin{array}{l}\text { Os atletas adotam diferentes estratégias de } \\
\text { conciliaçẫo entre os compromissos esportivos } \\
\text { e acadêmicos. Apoiados por mecanismos de } \\
\text { flexibilizaçãão das instituições acadêmicas com a } \\
\text { anuência dos pais }\end{array}$ \\
\hline BRA & ESP & 2013 & Soares, et al. & $\begin{array}{c}\text { Tiempo para el } \\
\text { futbol y la escuela: } \\
\text { un análisis de los } \\
\text { jóvenes jugadores } \\
\text { brasileños de Rio de } \\
\text { Janeiro }\end{array}$ & $\begin{array}{c}\text { ES } \\
\text { (México) }\end{array}$ & \begin{tabular}{|c|} 
Explorar e discutir a \\
influência do tempo \\
gasto nos treinamentos \\
esportivos na \\
conciliação com os \\
estudos
\end{tabular} & $Q Q$ & Futebol & M & CB & EB e ES & $\begin{array}{l}\text { Os atletas têm maior escolaridade do que a média } \\
\text { dos brasileiros de mesma faixa etária. A partir } \\
\text { dos } 15 \text { anos de idade a estratégia de conciliação } \\
\text { entre esporte e escolarização é a mudança para } \\
\text { o turno noturno da escola. As flexibilizações } \\
\text { que favorecem o cumprimento das obrigaçōes } \\
\text { esportivas e acadêmicas são feitas pela escola. }\end{array}$ \\
\hline BRA & POR & 2014 & $\begin{array}{l}\text { Melo; Soares; } \\
\text { Rocha }\end{array}$ & $\begin{array}{l}\text { Perfil educacional de } \\
\text { atletas em formação } \\
\text { no futebol no Estado } \\
\text { do Rio de Janeiro }\end{array}$ & $\begin{array}{l}\text { RBEFE } \\
\text { (Brasil) }\end{array}$ & \begin{tabular}{|} 
Descrever o perfil \\
escolar de atletas que \\
atuam no estado do \\
Rio de Janeiro e que se \\
encontram no período \\
da escolarização básica
\end{tabular} & $\mathrm{QQ}$ & Futebol & M & CB & $\mathrm{EB}$ & $\begin{array}{l}\text { Não foi observado abandono escolar, no entanto } \\
\text { percebe-se a mudança para o turno noturno } \\
\text { escolar o que pode afetar negativamente a } \\
\text { trajetória acadêmica. O sucesso esportivo passa } \\
\text { a ser um projeto familiar. Aparentemente quanto } \\
\text { maior os investimentos na carreira esportiva mais } \\
\text { secundarizam-se a acadêmica. }\end{array}$ \\
\hline $\mathrm{COL}$ & ESP & 2014 & Lagos Córtez & $\begin{array}{c}\text { Estrategias de } \\
\text { las Universidades } \\
\text { colombianas para } \\
\text { favorecer el acceso, } \\
\text { permanencia } \\
\text { y finalización } \\
\text { de estudios en } \\
\text { deportistas de alto } \\
\text { rendimiento }\end{array}$ & LP (Colômbia) & $\begin{array}{l}\text { Caracterizar as } \\
\text { diferentes estratégias } \\
\text { utilizadas pelas } \\
\text { universidades } \\
\text { colombianas para } \\
\text { favorecer o acesso, } \\
\text { a permanência e } \\
\text { a graduação de } \\
\text { alunos atletas de alto } \\
\text { rendimento }\end{array}$ & $Q Q$ & $\mathrm{NI}$ & $\mathrm{NI}$ & $\mathrm{NI}$ & ES & $\begin{array}{l}\text { As universidades colombianas ainda não se } \\
\text { comprometem com ações que apoiem de forma } \\
\text { contundente a formação acadêmica de atletas } \\
\text { de alto rendimento. Existe algum apoio aos } \\
\text { estudantes-attetas que se referem basicamente } \\
\text { a prática esportiva universitária, e não as } \\
\text { necessidades do atleta de alto rendimento. }\end{array}$ \\
\hline
\end{tabular}

7 Argentina (ARG); Brasil (BRA); Chile (CHI); Colômbia (COL); Cuba (CUB).

8 Idiomas de difusão: POR (português); ESP (espanhol); ING (inglês)

9 Revista Brasileira Ciências Esporte (RBCE); Estudios Sociológicos (ES); Revista Brasileira Educação Física Esporte (RBEFE); Lúdica Pedagógica (LP); Revista de Estudios e Investigación en Psicología y Educación (REIPE); Revista Brasileira de Futsal e Futebol (RBFF): Revista Brasileira Ciência e Movimento (RBCM): Temas em Educação Física Escolar (TEFE); Psicologia Revista São Paulo (PRSP); Revista @mbienteeducação (RAE); Revista Pensar a Prática (RPP); Arquivos de Ciências do Esporte (ACDE); Revista Motrivivência (RMV); Educación Física y Ciencia (EFC); Revista Educação Popular (REV); Caderno de Educação Física e Esporte (CEFE); Revista Eletrônica de Ciências Sociais (RECS); Revista Novos Olhares Sociais (RNOS); Revista Internacional Educação Superior (RIES); Journal of Physical Education (JPE); Revista Dilemas Contemporáneos: Educación, Política y Valores (RDCEPV); Revista Ciencias de la Actividad Física UCM (RCAF).

10 Cartografia (CA); Revisão (RE); Qualitativo (QL); Quantitativo (QT), Quantitativo-Qualitativo (QQ); Editorial (ED).

11 Feminino (F); Masculino (M); Não identificado (NI)

12 Esporte Escolar (EE); Categorias de Base (CB); Esporte Universitário (EU); Esporte de Elite (EL); Não identificado (NI).

13 Educação Básica (EB); Ensino Superior (ES).

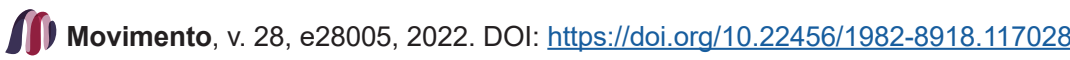




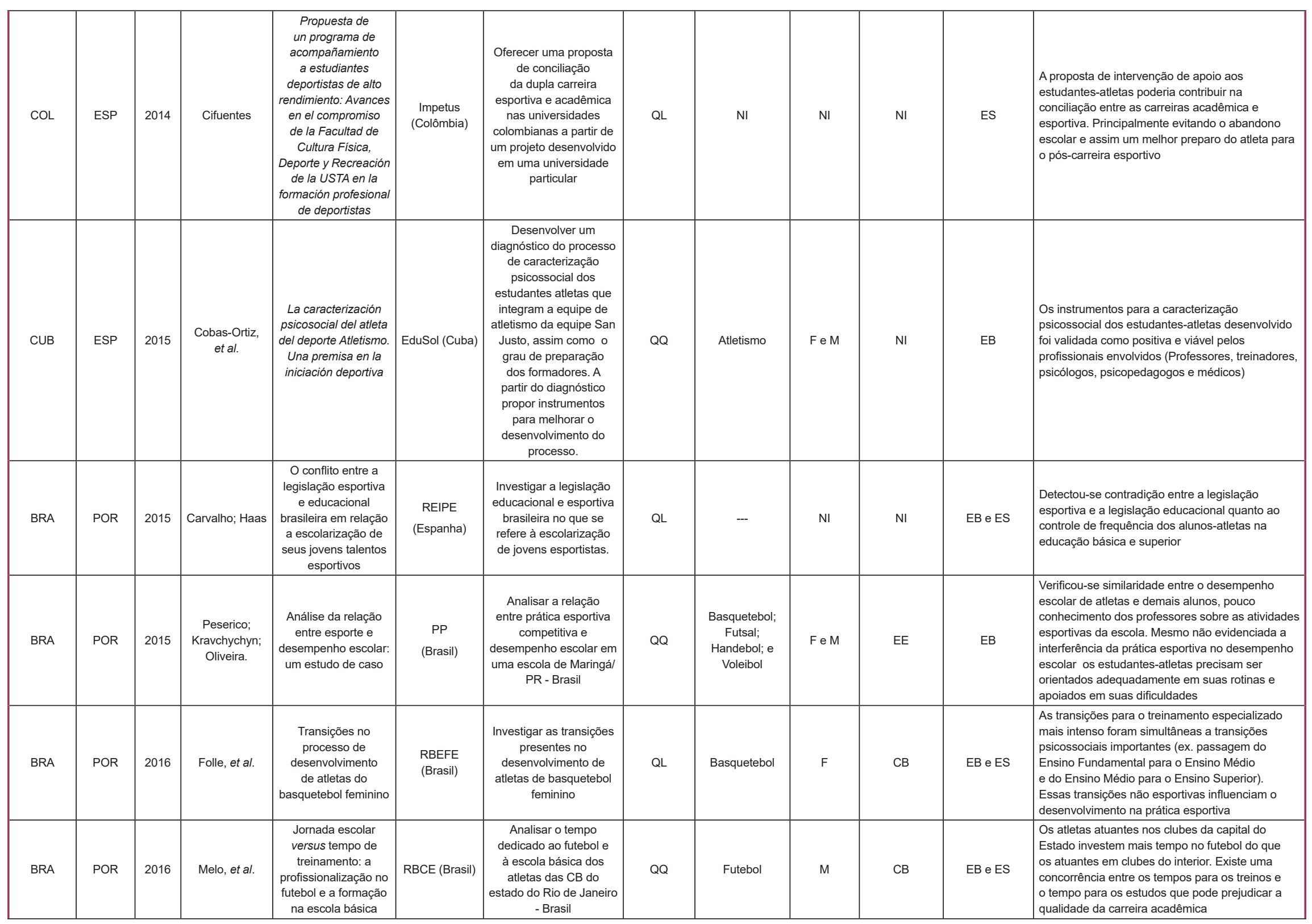

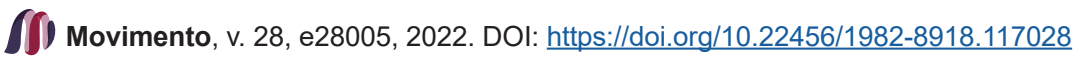




\begin{tabular}{|c|c|c|c|c|c|c|c|c|c|c|c|c|}
\hline COL & POR & 2016 & Cantor & $\begin{array}{l}\text { Programa de } \\
\text { acompañamiento } \\
\text { a estudiantes- } \\
\text { deportistas: una } \\
\text { experiencia exitosa } \\
\text { en la Universidad } \\
\text { Santo Tomás }\end{array}$ & $\begin{array}{l}\text { Impetus } \\
\text { (Colômbia) }\end{array}$ & \begin{tabular}{|c|} 
Descrever o programa \\
de acompanhamento \\
que busca harmonizar \\
a vida do estudante- \\
atleta na Faculdade de \\
Cultura Física, Desporto \\
e Recreação da \\
Universidade de Santo \\
Tomás \\
\end{tabular} & QL & $\mathrm{NI}$ & $\mathrm{NI}$ & $\mathrm{NI}$ & ES & $\begin{array}{l}\text { Os fundamentos e diretrizes do programa descrito, } \\
\text { bem como suas realizaçôes e perspectivas foi } \\
\text { reconhecido como um processo de sucesso }\end{array}$ \\
\hline BRA & POR & 2017 & $\begin{array}{l}\text { Correia; Silva; } \\
\text { Soares. }\end{array}$ & $\begin{array}{l}\text { Colégio Vasco } \\
\text { da Gama: notas } \\
\text { para pensar os } \\
\text { entrelaçamentos das } \\
\text { culturas escolares } \\
\text { com as práticas } \\
\text { esportivas }\end{array}$ & $\begin{array}{c}\text { Perspectiva } \\
\text { (Brasil) }\end{array}$ & \begin{tabular}{|c|} 
Indiciar aspectos \\
referentes aos possiveis \\
entrelaçamentos das \\
culturas escolares com \\
as práticas esportivas \\
em uma instituição de \\
ensino que funciona \\
dentro de uma \\
instituição esportiva \\
\end{tabular} & QL & $\begin{array}{l}\text { Atletismo e } \\
\text { Futebol }\end{array}$ & $\mathrm{FeM}$ & CB & EB & $\begin{array}{l}\text { As relações entre o colégio e o clube interferem, } \\
\text { nos saberes e práticas que, cotidianamente, são } \\
\text { construídos através da } \\
\text { interpenetração de elementos do esporte no } \\
\text { espaço da escola. Identificou-se um sentimento } \\
\text { de adesão à institucição escolar, por meio da } \\
\text { linguagem do esporte. }\end{array}$ \\
\hline BRA & POR & 2017 & Azevedo, et al. & $\begin{array}{l}\text { Formação escolar } \\
\text { e formação } \\
\text { esportiva: caminhos } \\
\text { apresentados pela } \\
\text { produçãao acadêmica }\end{array}$ & $\begin{array}{l}\text { Movimento } \\
\text { (Brasil) }\end{array}$ & $\begin{array}{c}\text { Mapear as produções } \\
\text { acadêmicas que } \\
\text { discutem a conciliação } \\
\text { entre formação escolar e } \\
\text { formação esportiva }\end{array}$ & RE & $\mathrm{NI}$ & $\mathrm{NI}$ & $\mathrm{NI}$ & EB e ES & $\begin{array}{l}\text { Foram encontrados } 17 \text { artigos. O tema da dupla } \\
\text { carreira surge na Europa e nos EUA, na década } \\
\text { de } 1970 \text {. No Brasil, passa a ser abordado na } \\
\text { década de 2000. Apresenta tentativas de } \\
\text { conciliação entre as formaçỗes e a importância de } \\
\text { fatores externos na } \\
\text { possibilidade de priorização de uma das } \\
\text { formações envolvidas }\end{array}$ \\
\hline BRA & POR & 2017 & Maciel, et al. & $\begin{array}{l}\text { Envolvimento } \\
\text { esportivo e escolar: } \\
\text { percepções de } \\
\text { alunos-atletas } \\
\text { do programa } \\
\text { "Basquetebol Para } \\
\text { Todos" }\end{array}$ & $\begin{array}{l}\text { RBCM } \\
\text { (Brasil) }\end{array}$ & \begin{tabular}{|l|} 
Analisar o envolvimento \\
acadêmico-esportivo \\
na perspectiva dos \\
estudantes-atletas \\
participantes do \\
Programa Basquetebol \\
Para Todos.
\end{tabular} & QT & Basquetebol & $\mathrm{FeM}$ & CB & EB & $\begin{array}{l}\text { Na percepção dos alunos-atletas, o envolvimento } \\
\text { esportivo naão modifica o tempo dedicado aos } \\
\text { estudos, bem como as demandas escolares não } \\
\text { alteram a presença nos treinos. Constatou-se } \\
\text { boa comunicação entre pais e treinadores com } \\
\text { relação ao desempenho esportivo e escolar dos } \\
\text { estudantes-atletas. }\end{array}$ \\
\hline BRA & POR & 2018 & $\begin{array}{l}\text { Costa; Rocha; } \\
\text { Cadavid. }\end{array}$ & $\begin{array}{l}\text { Sobre a dupla } \\
\text { carreira esportiva e o } \\
\text { direito à educação }\end{array}$ & TEFE (Brasil) & \begin{tabular}{|} 
Analisar como se \\
encontra a relação \\
entre a dupla \\
carreira esportiva \\
e a escolarizacăão \\
especialmente na \\
Universidade de Brasilia \\
(UnB)
\end{tabular} & ED & $\mathrm{NI}$ & $\mathrm{NI}$ & EU e ou EL & ES & $\begin{array}{l}\text { Os atletas demonstram bom índice acadêmico, } \\
\text { quebrando o estereotipo de que atletas não } \\
\text { estudam. Demostraram bom equilibrio entre } \\
\text { o tempo dedicado aos estudos e os horários } \\
\text { disponiveis. A ausência de políticas públicas } \\
\text { direcionadas para o estudante-atleta em situação } \\
\text { de dupla carreira acaba por deixar ao poder } \\
\text { discricionário das instituições as querelas das } \\
\text { rotinas. }\end{array}$ \\
\hline
\end{tabular}

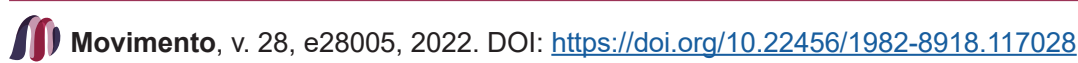


Christiano Streb Ricci, Rodrigo Aquino, Renato Francisco Rodrigues Marques

\begin{tabular}{|c|c|c|c|c|c|c|c|c|c|c|c|c|}
\hline BRA & POR & 2018 & \begin{tabular}{|c|} 
Fiochi- \\
Marques; \\
Oliveira; Melo- \\
Silva.
\end{tabular} & $\begin{array}{l}\text { Construção } \\
\text { da carreira do } \\
\text { universitário- } \\
\text { atleta: percepções } \\
\text { e expectativas } \\
\text { na transição } \\
\text { universidade-trabalho }\end{array}$ & $\begin{array}{l}\text { PRSP } \\
\text { (Brasil) }\end{array}$ & $\begin{array}{c}\text { Descrever as } \\
\text { perceppōoses e } \\
\text { expectativas de } \\
\text { universitários-atletas } \\
\text { sobre a construção } \\
\text { de suas carreiras na } \\
\text { transição aniversidade } \\
\text { trabalho } \\
\end{array}$ & QL & $\begin{array}{l}\text { Atletismo, } \\
\text { Basquetebol e } \\
\text { Handebol }\end{array}$ & M & EU & ES & $\begin{array}{l}\text { Os participantes indicaram: Envolvimento } \\
\text { esportivo desde a infância; Interesse pelo esporte } \\
\text { como critério de escolha do curso superior; } \\
\text { Saliência entre os papéis de estudante e atleta; } \\
\text { Falta de apoio institucional. }\end{array}$ \\
\hline BRA & POR & 2018 & Haas; Carvalho & $\begin{array}{c}\text { Escolarização dos } \\
\text { talentos esportivos: } \\
\text { busca pelo sucesso } \\
\text { no esporte, } \\
\text { distanciamento da } \\
\text { escola e conflitos } \\
\text { legais }\end{array}$ & $\begin{array}{l}\text { RAE } \\
\text { (Brasil) }\end{array}$ & $\begin{array}{l}\text { Investigar a evasão } \\
\text { escolar dos estudantes } \\
\text { atletas na educação } \\
\text { superior e verificar } \\
\text { se a legislação } \\
\text { educacional e esportiva } \\
\text { brasileira favorece } \\
\text { aos jovens esportistas } \\
\text { a permanecerem na } \\
\text { Universidade }\end{array}$ & QL & $\mathrm{NI}$ & $\mathrm{NI}$ & EU e EL & ES & $\begin{array}{l}\text { Identificou-se uma contradicãa entre a legislação } \\
\text { esportiva e a legislação educacional, no que se } \\
\text { refere ao controle de frequência dos estudantes- } \\
\text { atletas; observou-se que o esporte, para esse } \\
\text { grupo, representa uma alternativa de ascensão } \\
\text { social e econômica, às vezes, mais } \\
\text { atraente do que a educação universitária. }\end{array}$ \\
\hline BRA & POR & 2018 & $\begin{array}{l}\text { Andres; } \\
\text { Goellner }\end{array}$ & $\begin{array}{l}\text { Trajetórias esportivas } \\
\text { de jogadoras de } \\
\text { handebol e suas } \\
\text { narrativas sobre } \\
\text { ser profissional da } \\
\text { modalidade }\end{array}$ & $\begin{array}{c}\text { Movimento } \\
\text { (Brasil) }\end{array}$ & \begin{tabular}{|l|} 
Analisar o processo de \\
profissionalização de \\
atletas praticantes de \\
handebol de um time \\
do Rio Grande do Sul, \\
considerando suas \\
trajetórias e narrativas
\end{tabular} & QL & Handebol & $\mathrm{F}$ & EL & EB e ES & $\begin{array}{l}\text { O entendimento que as atletas expressam } \\
\text { sobre ser uma profissional da modalidade se } \\
\text { dá mediante a relação que estabelecem com } \\
\text { a prática do esporte e não a partir de vínculos } \\
\text { trabalihistas que façam dessa atividade uma } \\
\text { profissão. }\end{array}$ \\
\hline BRA & POR & 2018 & Reis, et al. & \begin{tabular}{|l} 
Como ocorreu \\
o processo de \\
término da carreira \\
esportiva de ex- \\
atletas de futebol que \\
disputaram Copas \\
do Mundo pelo Brasil \\
entre 1966 e 1982 ?
\end{tabular} & $\begin{array}{l}\text { RPP } \\
\text { (Brasil) }\end{array}$ & $\begin{array}{c}\text { Analisar o término da } \\
\text { carreira de ex-atletas de } \\
\text { futebol que disputaram } \\
\text { Copas do Mundo pelo } \\
\text { Brasil entre } 1966 \mathrm{e} \\
1982 .\end{array}$ & QL & Futebol & M & EL & & $\begin{array}{l}\text { Os ex-atletas não tiveram acesso a uma estrutura } \\
\text { profissional para planejar o término da carreira. } \\
\text { Não conseguiram conciliar a carreira esportiva } \\
\text { com os estudos. }\end{array}$ \\
\hline BRA & POR & 2018 & Souza; Martins & $\begin{array}{l}\text { O paradoxo da } \\
\text { profissionalização } \\
\text { do futsal feminino } \\
\text { no Brasil: entre o } \\
\text { esporte e outra } \\
\text { carreira }\end{array}$ & $\begin{array}{l}\text { RPP } \\
\text { (Brasil) }\end{array}$ & $\begin{array}{l}\text { Descrever o perfil das } \\
\text { atletas e o contexto } \\
\text { do futsal feminino no } \\
\text { estado de São Paulo; } \\
\text { Analisar a relação entre } \\
\text { o perfil socioeconômico, } \\
\text { a formação esportiva e a } \\
\text { carreira esportiva }\end{array}$ & QT & Futsal & $\mathrm{F}$ & EL & EB e ES & $\begin{array}{l}\text { A carreira no futsal de mulheres é pouco } \\
\text { estruturada. A carreira no futsal se constitui em } \\
\text { um paradoxo, pois não é um projeto de vida em } \\
\text { si, mas fonte de acesso a outro, que pode se } \\
\text { consolidar como uma possibiliade de mudança } \\
\text { social para elas por meio do acesso à educação } \\
\text { via esporte. }\end{array}$ \\
\hline
\end{tabular}

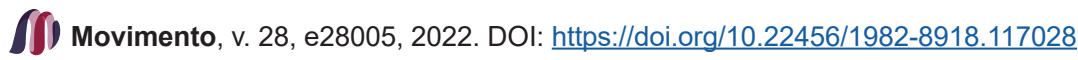




\begin{tabular}{|c|c|c|c|c|c|c|c|c|c|c|c|c|}
\hline BRA & POR & 2018 & Verzani, et al. & $\begin{array}{l}\text { Desafios da dupla } \\
\text { carreira na formação } \\
\text { de futebolistas: olhar } \\
\text { sobre a escolaridade }\end{array}$ & ACDE (Brasil) & \begin{tabular}{|c|} 
Analisar o nivel de \\
escolaridade de atletas \\
da categoria sub-20 \\
em disputa da principal \\
competição de futebol \\
desta categoria no \\
Brasil entre os anos de \\
2010 e $2015 ;$ Discutir \\
os possiveis reflexos da \\
dupla carreira
\end{tabular} & QT & Futebol & M & $\mathrm{CB}$ & EB & $\begin{array}{l}\text { Os atletas formados no ensino médio aumentaram } \\
\text { de } 44,5 \% \text { em } 2010 \text { para } 67,39 \% \text { em } 2015 \text {. }\end{array}$ \\
\hline BRA & POR & 2019 & $\begin{array}{l}\text { Belato; } \\
\text { Carneiro; } \\
\text { Athayde. }\end{array}$ & $\begin{array}{c}\text { Análise do programa } \\
\text { Bolsa Alteta } \\
\text { universitária na } \\
\text { Universidade de } \\
\text { Brasilia de 2011 a } \\
2015\end{array}$ & $\begin{array}{l}\text { RMV } \\
\text { (Brasil) }\end{array}$ & $\begin{array}{l}\text { Analisar o Programa } \\
\text { Bolsa Atleta Universitária } \\
\text { da Universidade de } \\
\text { Brasilia (PBA-UnB) no } \\
\text { periodo de } 2011 \text { a } 2015\end{array}$ & $\mathrm{QQ}$ & $\mathrm{NI}$ & $\mathrm{NI}$ & EU e EL & ES & $\begin{array}{l}\text { O PBA-UnB possui abrangência restrita } \\
\text { e atendimento focalizado com potencial } \\
\text { de ampliação. O programa oscila entre a } \\
\text { hegemonia dos padrões de avaliação do esporte } \\
\text { de rendimento e o alinhamento à política } \\
\text { universitária e ao papel democrático e inclusivo da } \\
\text { Universidade pública. }\end{array}$ \\
\hline ARG & ESP & 2019 & Laíño, et al. & $\begin{array}{l}\text { Educacion formal } \\
\text { y deporte de élite } \\
\text { en adolescentes } \\
\text { argentinos }\end{array}$ & $\begin{array}{c}\mathrm{EFC} \\
\text { (Argentina) }\end{array}$ & $\begin{array}{l}\text { Identificar barreiras } \\
\text { e facilitadores para } \\
\text { os representantes } \\
\text { argentinos dos Jogos } \\
\text { Olímpicos da Juventude } \\
\text { de } 2018\end{array}$ & $\mathrm{QQ}$ & $\begin{array}{l}\text { Várias } \\
\text { modalidades }\end{array}$ & $\mathrm{FeM}$ & $\mathrm{CB}$ & $\mathrm{EB}$ & $\begin{array}{l}\text { Barreiras: Apenas } 27 \% \text { dos participantes recebem } \\
\text { algum tipo de tutoria para apoiar a os estudos } \\
\text { e treinamentos esportivos; cerca de } 30 \% \text { dos } \\
\text { participantes relatam não ter apoio das instituições } \\
\text { para a conciliação das atividades escolares e } \\
\text { esportivas; } 38 \% \text { relatam que o cansaço dos } \\
\text { treinos afeta os estudos. } \\
\text { Facilitadores: } 76 \% \text { dos participantes têm algum } \\
\text { tipo de flexibilização para fazer as avaliações } \\
\text { escolares; } 70 \% \text { dos participantes consideram } \\
\text { entre bom e satisfatório o suporte das instituições. } \\
\text { Quase } 90 \% \text { dos participantes gostariam de } \\
\text { ingressar no Ensino Superior. }\end{array}$ \\
\hline BRA & POR & 2019 & Moro; Berticelli & $\begin{array}{c}\text { Jovens-pobres- } \\
\text { jogadores de futebol } \\
\text { e suas possibilidades } \\
\text { escolares: uma } \\
\text { cartografia da } \\
\text { educação escolar } \\
\text { dos jogadores } \\
\text { das CB do futebol } \\
\text { brasileiro }\end{array}$ & $\begin{array}{l}\text { REV } \\
\text { (Brasil) }\end{array}$ & $\begin{array}{l}\text { Compreender, por meio } \\
\text { da cartografia, } \\
\text { como o processo de } \\
\text { subjetivação do jogador } \\
\text { de futebol em formação } \\
\text { produz sentidos acerca } \\
\text { da educação escolar }\end{array}$ & $\mathrm{CA}$ & Futebol & M & $\mathrm{CB}$ e EL & $E B$ e ES & $\begin{array}{l}\text { A educação escolar para jovens-jogadores } \\
\text { advindos de familias pobres se apresenta a partir } \\
\text { de duas possibilidades: a educação } \\
\text { escolar clubística ou a educação para jovens e } \\
\text { adultos. Pouco jogadores- } \\
\text { universitários foram encontrados os quais } \\
\text { percebem o ambiente educacional como } \\
\text { uma linha de fuga para romper o padrão } \\
\text { hegemônico de formaçãoo esportiva oferecida } \\
\text { pelas CB do futebol brasileiro. }\end{array}$ \\
\hline BRA & POR & 2019 & $\begin{array}{l}\text { Rastelli; } \\
\text { Bandeira }\end{array}$ & $\begin{array}{c}\text { "E aí? Como vai } \\
\text { a escola?": uma } \\
\text { revisão sistemática } \\
\text { sobre o papel da } \\
\text { formação esportiva } \\
\text { no processo de } \\
\text { escolarização de } \\
\text { atletas adolescentes }\end{array}$ & $\begin{array}{l}\text { RPP } \\
\text { (Brasil) }\end{array}$ & $\begin{array}{l}\text { Investigar o impacto } \\
\text { da formacăão esportiva } \\
\text { na escolarização de } \\
\text { atletas adolescentes } \\
\text { que cursam a educação } \\
\text { básica }\end{array}$ & $\mathrm{RE}$ & $\mathrm{NI}$ & $\mathrm{NI}$ & $\mathrm{NI}$ & EB & $\begin{array}{l}\text { Oito estudos analisados. A escola é compreendida } \\
\text { como fundamental pelo fato de mobilizar } \\
\text { estratégias para a permanência dos atletas na } \\
\text { instituição. Pais e professores também possuem } \\
\text { responsabilidade no processo }\end{array}$ \\
\hline
\end{tabular}

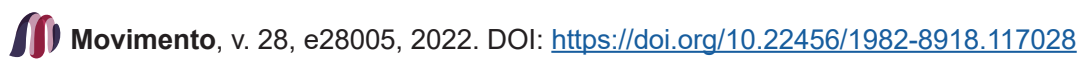


Christiano Streb Ricci, Rodrigo Aquino, Renato Francisco Rodrigues Marques

\begin{tabular}{|c|c|c|c|c|c|c|c|c|c|c|c|c|}
\hline BRA & POR & 2020 & Bagni et al. & $\begin{array}{l}\text { Agentes estressores } \\
\text { e o enfrentamento } \\
\text { de problemas } \\
\text { em tenistas e } \\
\text { mesatenistas } \\
\text { universitários }\end{array}$ & CEFE (Brasil) & $\begin{array}{l}\text { Analisar as estratégias } \\
\text { de enfrentamento } \\
\text { utilizadas por atletas } \\
\text { universitários de } \\
\text { esportes de raquete, } \\
\text { bem como verificar as } \\
\text { situaçōes estressoras } \\
\text { enfrentadas por eles. }\end{array}$ & $Q Q$ & $\begin{array}{l}\text { Esportes de } \\
\text { raquete }\end{array}$ & M & EU & ES & $\begin{array}{l}\text { Os atletas utilizam estratégias de enfrentamento } \\
\text { eficientes e encontra mais dificuldades em } \\
\text { conciliar a dupla carreira (estudante-atleta). } \\
\text { Torna-se necessário uma maior percepção por } \\
\text { parte dos gestores do esporte universitário acerca } \\
\text { deste tópico, sendo ainda necessário maiores } \\
\text { estudos neste tópico, visando auxiliar os atletas } \\
\text { e proporcionar um maior rendimento esportivo e } \\
\text { acadêmico para eles. }\end{array}$ \\
\hline BRA & POR & 2020 & Conceição; Vaz & $\begin{array}{l}\text { A concomitância } \\
\text { entre estudare } \\
\text { jogar: observaçōes } \\
\text { sobre o processo } \\
\text { de descontinuidade } \\
\text { na escolarização de } \\
\text { jogadores de futebol } \\
\text { em formaçăo }\end{array}$ & RECS (Brasil) & $\begin{array}{l}\text { Abordar a formação } \\
\text { de atletas no futebol } \\
\text { de campo e sua } \\
\text { relação com a escola, } \\
\text { apresentando parte dos } \\
\text { resultados obtidos em } \\
\text { pesquisa com as CB de } \\
\text { dois clubes profissionais } \\
\text { de Santa Catarina } \\
\end{array}$ & $\mathrm{QQ}$ & Futebol & M & CB e EL & EB & $\begin{array}{l}\text { A atual formação esportiva no futebol de campo } \\
\text { favorece a descontinuidade na relação que o } \\
\text { atleta constrói com a escola e consequentemente } \\
\text { com a sua escolarização. }\end{array}$ \\
\hline BRA & POR & 2020 & $\begin{array}{l}\text { Correia; } \\
\text { Soares }\end{array}$ & $\begin{array}{l}\text { Dilemas da dupla } \\
\text { carreira: projeto } \\
\text { escolar e futebolístico } \\
\text { de estudantes-atletas } \\
\text { das classes médias } \\
\text { e altas do Rio de } \\
\text { Janeiro }\end{array}$ & RECS (Brasil) & $\begin{array}{c}\text { Analisar por meio dos } \\
\text { conceitos de projeto e } \\
\text { campo de possibilidades } \\
\text { de Gilberto Velho as } \\
\text { estratégias e crenças } \\
\text { de estudantes-atletas } \\
\text { pertencentes à classe } \\
\text { média e alta do Rio de } \\
\text { Janeiro no que tange a } \\
\text { sua profissionalização } \\
\text { e escolarização (dupla } \\
\text { carreira) } \\
\end{array}$ & QL & Futebol & $\mathrm{M}$ & CB & $E B$ & $\begin{array}{l}\text { O campo de possibilidades dos jovens e a } \\
\text { trajetória familiar influenciavam na construção das } \\
\text { suas crenças e consequentemente na maneira } \\
\text { como elaboravam estratégias na escolarização } \\
\text { e na formação futebolistica. As condiçôes } \\
\text { econômicas e mais alto capital cultural familiar } \\
\text { demonstram um projeto de dupla carreira mais } \\
\text { equilibrado. }\end{array}$ \\
\hline BRA & POR & 2020 & $\begin{array}{l}\text { Correia; Melo; } \\
\text { Soares. }\end{array}$ & $\begin{array}{l}\text { Mercado esportivo } \\
\text { e escolarização de } \\
\text { mulheres atletas }\end{array}$ & RNOS (Brasil) & $\begin{array}{c}\text { Problematizar as } \\
\text { desigualdades } \\
\text { esportivas e como as } \\
\text { mulheres administram } \\
\text { a dupla carreira de } \\
\text { formação no esporte } \\
\text { e na escolarização, } \\
\text { em diferentes niveis, e } \\
\text { os possivieis impactos } \\
\text { dessa administração no } \\
\text { mercado da modalidade }\end{array}$ & QL & $\mathrm{NI}$ & $\mathrm{NI}$ & $\mathrm{NI}$ & $\mathrm{NI}$ & $\begin{array}{l}\text { A existência de esportes com mercados } \\
\text { mais consolidados e expandidos pode } \\
\text { significar, aos olhos das atletas, um campo de } \\
\text { possibilidades maior para a profissionalização } \\
\text { e, consequentemente, um direcionamento maior } \\
\text { para a prática esportiva em detrimento de outras } \\
\text { atividades, entre elas a formação escolar. }\end{array}$ \\
\hline BRA & ING & 2020 & $\begin{array}{c}\text { Martins; } \\
\text { Rocha; Costa. }\end{array}$ & \begin{tabular}{|l} 
A Narrative Review \\
on Student- Athletes \\
in Higher Education: \\
Barriers, Solutions \\
and Satisfactory \\
Post-Sport Career \\
Transition
\end{tabular} & RIES (Brasil) & $\begin{array}{l}\text { Analisar a conciliação } \\
\text { entre esporte e } \\
\text { formação acadêmica de } \\
\text { alunos-atletas do ensino } \\
\text { superior }\end{array}$ & RE & $\mathrm{NI}$ & $\mathrm{NI}$ & EL & ES & $\begin{array}{l}14 \text { artigos analisados. Os estudantes-atletas } \\
\text { encontram diferentes barreiras relacionadas } \\
\text { ao estereétipo de inferioridade intelectual que } \\
\text { lhes é atribuído, à sua rotina de treinamento } \\
\text { e à preparação para a vida após o esporte. } \\
\text { O incentivo aos objetivos acadêmicos e a } \\
\text { compreensão das instituições de ensino sobre } \\
\text { as dificuldades encontradas pelos alunos-atletas } \\
\text { foram apontados como meios de superar as } \\
\text { barreiras relacionadas ao estereótipo negativo. } \\
\text { A participação em atividades que promovam o } \\
\text { desenvolvimento profissional em conjunto com } \\
\text { a oferta de cursos online durante os períodos de } \\
\text { preparação para competiçôes é indicada como } \\
\text { estratégia para uma transição pós-desportiva } \\
\text { profissional satisfatória. }\end{array}$ \\
\hline
\end{tabular}

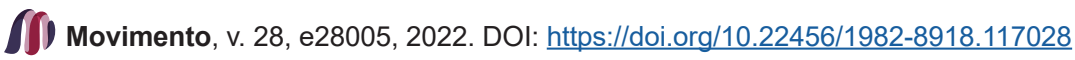




\begin{tabular}{|c|c|c|c|c|c|c|c|c|c|c|c|c|}
\hline BRA & POR & 2020 & $\begin{array}{l}\text { Melo; Rocha; } \\
\text { Romão. }\end{array}$ & $\begin{array}{c}\text { Dupla carreira: } \\
\text { dilemas entre esporte } \\
\text { e escola }\end{array}$ & $\begin{array}{c}\text { JPE } \\
\text { (Brasil) }\end{array}$ & $\begin{array}{c}\text { Analisar os modelos de } \\
\text { conciliação das rotinas } \\
\text { na dupla carreira, } \\
\text { esportiva e escolar, no } \\
\text { Programa Bolsa Atleta } \\
\text { do Governo Federal, } \\
\text { com estudantes-atletas } \\
\text { contemplados pelos } \\
\text { resultados obtidos no } \\
\text { ano de 2011. } \\
\end{array}$ & QT & $\begin{array}{l}\text { Atletismo, Judô } \\
\text { e Natação }\end{array}$ & $\mathrm{FeM}$ & $\mathrm{CB}$ e EL & EB e ES & $\begin{array}{l}\text { As diferentes modalidades esportivas exigem } \\
\text { dos seus atletas tempo e dedicacãão distintos; } \\
\text { O processo de iniciação nas três modalidades } \\
\text { exige diferentes formas de investimentos; Os } \\
\text { pais e os atletas do atletismo apresentaram } \\
\text { menor escolaridade, assim como, classe social } \\
\text { mais baixa. Diante dos obstáculos da dupla } \\
\text { carreira, atletas, clube, escola e famillias passam } \\
\text { adotorar táticas de conciliação e mesmo burla dos } \\
\text { programas de suporte à formação esportiva. }\end{array}$ \\
\hline BRA & POR & 2020a & $\begin{array}{c}\text { Miranda; } \\
\text { Loreno; Costa. }\end{array}$ & \begin{tabular}{|c|} 
A dupla jornada do \\
atleta universitário: \\
perspectivas para \\
a conciliação entre \\
estudos e treinos \\
na Universidade de \\
Brasilia
\end{tabular} & $\begin{array}{l}\text { Movimento } \\
\text { (Brasil) }\end{array}$ & $\begin{array}{l}\text { Apresentar e analisar } \\
\text { o perfil dos estudantes } \\
\text { atletas da Univ. } \\
\text { de Brasilia (UnB) } \\
\text { que representaram } \\
\text { a instituiçãa em } \\
\text { competicōes } \\
\text { universitárias entre } 2017 \\
\text { e } 2018 \\
\end{array}$ & QL & $\begin{array}{c}17 \text { modalidades } \\
\text { e E-games }\end{array}$ & $\mathrm{FeM}$ & EU & ES & $\begin{array}{l}\text { Os resultados apresentam o êxito na politica de } \\
\text { representação promovida pela UnB e relativo } \\
\text { sucesso na conciliação da dupla jornada dos } \\
\text { estudantes atletas, apesar de a maioria dos } \\
\text { attetas terem alcançado resultados nacionais e } \\
\text { internacionais. }\end{array}$ \\
\hline BRA & POR & 2020b & $\begin{array}{c}\text { Miranda; } \\
\text { Santos; Costa. }\end{array}$ & $\begin{array}{l}\text { Dupla carreira de } \\
\text { estudantes atletas: } \\
\text { uma revisão } \\
\text { sistemática nacional }\end{array}$ & RMV (Brasil) & $\begin{array}{l}\text { Analisar a produção } \\
\text { brasileira sobre a } \\
\text { escolarização de atletas } \\
\text { em artigos divulgados } \\
\text { em português }\end{array}$ & RE & $\mathrm{NI}$ & $\mathrm{NI}$ & $\mathrm{NI}$ & $\mathrm{NI}$ & $\begin{array}{l}7 \text { artigos encontrados. O predomínio de estudos } \\
\text { descritivos sobre o perfil de jovens futebolistas } \\
\text { e dois estudos de revisão sobre o mercado do } \\
\text { futebol e marcos legais para atletas estudantes. } \\
\text { A administração do tempo entre as duas jornadas } \\
\text { e a ausência de regulamentação especifica na } \\
\text { legislação esportiva são os principais desafios } \\
\text { para o desempenho da dupla carreira, os quais } \\
\text { são amenizados principalmente pelo suporte } \\
\text { familiar presente na flexibilização da formação } \\
\text { escolar. }\end{array}$ \\
\hline ARG & ESP & 2020 & $\begin{array}{l}\text { Murzi; Herbella; } \\
\text { Sustas. }\end{array}$ & $\begin{array}{l}\text { Ser futbolista juvenil } \\
\text { en Argentina. } \\
\text { Origenes, } \\
\text { escolarización, } \\
\text { vivienda, } \\
\text { sentimientos y } \\
\text { expectativas de } \\
\text { los depoortistas en } \\
\text { formación de un club } \\
\text { de fútbol profesional }\end{array}$ & $\begin{array}{l}\text { RDCEPV } \\
\text { (México) }\end{array}$ & $\begin{array}{l}\text { Traçar um perfil } \\
\text { sociodemográfico dos } \\
\text { jogadores de futebol na } \\
\text { Argentina a partit da } \\
\text { análise das mútitlas } \\
\text { dimensões da vida }\end{array}$ & QT & Futebol & M & $\mathrm{CB}$ e EL & EB e ES & $\begin{array}{l}15 \% \text { dos atletas abandonaram os estudos; } 80 \% \\
\text { estão estudando ou já concluirram o ensino básico; } \\
30 \% \text { dos concluintes ingressaram no Ensino } \\
\text { Superior; Os atletas alojados abandonam menos } \\
\text { a escola (existe uma pressão do clube para que } \\
\text { eles frequentem as aulas). A principal causa do } \\
\text { abandono é a dificuldade em conciliar o tempo de } \\
\text { estudo com treinos/jogos. Os atletas de grupos } \\
\text { menos favorecidos socioeconômicos e com pais } \\
\text { dom menos capital cultural institucionalizado } \\
\text { tem mais receio em não conseguir sucesso no } \\
\text { esporte. }\end{array}$ \\
\hline $\mathrm{CHI}$ & ESP & 2020 & $\begin{array}{l}\text { Aguilar; } \\
\text { Flández }\end{array}$ & \begin{tabular}{|c|} 
Identificación \\
de factores \\
obstaculizadores del \\
proceso académico \\
en deportistas \\
federados y de elite \\
em Chile
\end{tabular} & RCAF (Chile) & $\begin{array}{c}\text { Identificar fatores } \\
\text { impenititos associados } \\
\text { ao processo acadêmico, } \\
\text { de atletas federados e } \\
\text { de elite no Chile, em } \\
\text { particular a disciplina } \\
\text { de Remo }\end{array}$ & $\mathrm{QQ}$ & Remo & $\mathrm{FeM}$ & EL & ES & $\begin{array}{l}\text { A preocupação com alguns fatores impeditivos } \\
\text { que ocorrem no meio acadêmico, afeta o } \\
\text { desempenho esportivo. Isso não Ihes dá o foco } \\
\text { ea tranquilididade neecesários para garantir a } \\
\text { otimização de suas capacidades no campo } \\
\text { acadêmico e esportivo. }\end{array}$ \\
\hline BRA & POR & 2020 & $\begin{array}{l}\text { Pedroza Júnior, } \\
\quad \text { et al. }\end{array}$ & \begin{tabular}{|c|} 
História de vida \\
de ex-jogadores \\
profissionais \\
de futebol em \\
Pernambuco: \\
formação acadêmica \\
versus formação \\
esportiva
\end{tabular} & $\begin{array}{l}\text { Movimento } \\
\text { (Brasil) }\end{array}$ & $\begin{array}{l}\text { Analisar a relação } \\
\text { entre o processo de } \\
\text { formação acadêmica e } \\
\text { a formação esportiva } \\
\text { de ex-jogadores } \\
\text { profissionais de futebol } \\
\text { em Pernambuco }\end{array}$ & QL & Futebol & M & EL & EB e ES & $\begin{array}{l}\text { Os participantes, relataram dificuldade na } \\
\text { conciliação entre as duas carreiras, resultando } \\
\text { em defasagem, reprovaçōes, mudanças de turno } \\
\text { e até mesmo de abandono escolar. }\end{array}$ \\
\hline
\end{tabular}

Fonte: Dados da pesquisa

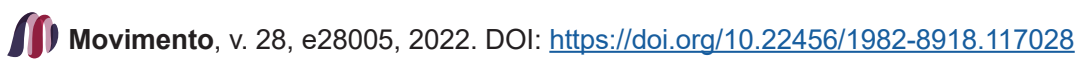

